\title{
43. VELOCITY AND DENSITY OF SEDIMENTS OF EIRIK RIDGE, LABRADOR SEA: CONTROL BY POROSITY AND MINERALOGY ${ }^{1}$
}

\author{
Richard D. Jarrard, ${ }^{2}$ Kathleen A. Dadey, ${ }^{3}$ and William H. Busch ${ }^{4}$
}

\begin{abstract}
A 767-m section of late Neogene (0-8 Ma) terrigenous sediments was cored at Ocean Drilling Program (ODP) Site 646. Continuous downhole geophysical logs, 161 laboratory measurements of core porosity and density, and 63 laboratory measurements of core velocity are used to analyze in detail the effects of porosity and mineralogy on the acoustic properties at this site. Porosity (determined from a resistivity log) agrees well with rebound-corrected laboratory measurements. Mineralogical variations (potassium feldspar, quartz plus plagioclase, calcite plus opal, and clay minerals) for the interval 206-737 mbsf were determined by matrix inversion of three logs: bound water, potassium, and uranium/ thorium ratio. These calculated mineralogical variations are similar in major features to mineral abundances from smear slides, but the wide depth spacing of smear slides and their subjective, semiquantitative mineral abundances preclude a detailed comparison. Calculated grain densities from mineralogy are consistent with laboratory measurements. A pseudodensity log from porosity and grain density is similar in character to the rebound-corrected, bulk-density measurements on cores, but about $0.1 \mathrm{~g} / \mathrm{cm}^{3}$ lower than core measurements in the interval $340-737 \mathrm{mbsf}$.

We found from our analyses that a strong synergy exists between downhole geophysical logs and core measurements of porosity and density: (1) core recovery is best at shallow depths, and logs are more reliable at greater depths; and (2) agreement between laboratory and log measurements corroborates the different assumptions made when analyzing the two data types. At Site 646, this synergy does not extend to laboratory measurements of velocity; laboratory velocities are lower than in-situ velocities, but higher than expected when rebound is considered.

Observed trends of laboratory and log porosity, density, and velocity as a function of depth at Site 646 are in reasonable agreement with empirical trends. In contrast, empirical relationships of velocity to porosity do not agree well with our data. Application of Hookean elastic equations to our data is hampered by the lack of shear wave velocities and the sensitivity of the technique to small errors in porosities. Nevertheless, this theoretical approach yields a pseudovelocity $\log$ that agrees remarkably well with observed in-situ log velocities.
\end{abstract}

\section{INTRODUCTION}

The terrigenous sediments of the northeast Labrador Sea provide a high-resolution record of Neogene changes in bottomwater activity. During Leg 105, two holes were drilled at Site 646 $\left(58^{\circ} 12.56^{\prime} \mathrm{N}, 48^{\circ} 22.15^{\prime} \mathrm{W}\right)$ on the Eirik Ridge, in a water depth of $3451 \mathrm{~m}$. Hole $646 \mathrm{~A}$ was hydraulic-piston cored to a depth of 103.5 mbsf, and Hole $646 \mathrm{~B}$ was cored with both the hydraulicpiston corer and extended-core barrel to a total depth of 766.7 mbsf. Both holes were continuously cored and had an overall average recovery of $55.7 \%$.

Here, we focus on the continuous downhole geophysical logs and discrete physical-properties measurements at Site 646. Our goals are to evaluate (1) the reliability of both types of measurements, (2) the extent to which velocity and density of these sediments are controlled by mineralogy and porosity, and (3) the consistency of these data with published empirical and theoretical models of porosity, velocity, and density variations as a function of depth and each other. In a companion paper (Busch, this volume), the porosity and compaction trend at Site 646 is analyzed in the context of trends at Sites 645 and 647 and in other terrigenous sequences. In a second companion paper (Jarrard and Arthur, this volume), the paleoceanographic implications of porosity and velocity variations at Site 646 are considered.

${ }^{1}$ Srivastava, S. P., Arthur, M., Clement, B., et al., 1989. Proc. ODP, Sci. Results, 105: College Station, TX (Ocean Drilling Program).

2 Lamont-Doherty Geological Observatory of Columbia Univ., Palisades, NY 10964.

${ }^{3}$ Graduate School of Oceanography, Univ. of Rhode Island, Narragansett, RI 02882.

${ }^{4}$ Department of Geology and Geophysics, Univ. of New Orleans, New Orleans, LA 70148.
Shipboard measurements of physical properties of core samples at Site 646 include 161 measurements of bulk density, grain density, and porosity, and 63 measurements of compressional wave velocity. The techniques used for density/porosity measurements (pycnometer) and velocity measurements (Hamilton frame velocimeter) are described in Srivastava, Arthur, et al., (1987a). With pipe set at $205 \mathrm{mbsf}$, the openhole interval from 205-742 mbsf at Hole 646B was logged with Schlumberger longspaced sonic, spherically focused, dual-induction, gamma ray, and caliper tools. Nearly the entire drilled interval from the seafloor to $743 \mathrm{mbsf}$ was logged with spectral gamma ray, neutron porosity, and gamma spectroscopy tools (Srivastava, Arthur, et al., 1987b). In general, the quality and depth distributions of these physical-property measurements and geophysical logs complement each other. Because of decreasing core recovery downhole, $49 \%$ of the porosity and density measurements are from the upper $206 \mathrm{~m}$ of the site. In contrast, geophysical logs were of higher quality and number in the openhole interval below 206 mbsf; the through-pipe logs were not used in our analyses. Shipboard interpretation of both logs and physical-properties measurements are discussed in Srivastava, Arthur, et al., (1987b).

The sedimentary sequence penetrated at Site 646 consists almost entirely of silty clays and clayey silts, deposited at a relatively uniform sedimentation rate of $90 \mathrm{~m} / \mathrm{m}$.y. during the last 8.5 m.y. (Srivastava, Arthur, et al., 1987b). The sequence is divided into two lithologic units on the basis of visual core descriptions and smear slides. Lithologic Unit I (0-236.4 mbsf, Holocene to late Pliocene) is divided into two subunits. Subunit IA (0-188.2 mbsf) consists of silty clays and clayey silts containing up to $40 \%$ carbonate and frequent ice-rafted dropstones. Subunit IB (188.2-236.4 mbsf) consists of poorly sorted muddy sands and silty muds, with frequent dropstones and an average of $10 \%$ carbonate. Glacial/interglacial cycles apparent in Sub- 
unit IA are associated with fluctuations in biocarbonate content, magnetic susceptibility, color variations, microfossil abundance, and dropstone abundance. The onset of major ice rafting occurs at the base of Subunit IA, at about $2.5 \mathrm{Ma}$. Thin units, interpreted as turbidites from the Northwest Atlantic MidOcean Channel, are common in Subunit IA, and sedimentary textures throughout this subunit are probably influenced by bottom-current activity. In contrast, the poorly sorted sediments of Subunit IB show little evidence of bottom-current activity and are probably dominated by ice-rafted supply (Srivastava, Arthur, et al., 1987b).

Lithologic Unit II (236.4-766.7 mbsf, late Pliocene to late Miocene) is predominantly silty clay, clayey silt, and clay, with a variable carbonate component composed primarily of nannofossils. This unit is visually homogeneous, partially because of extensive bioturbation. Unit II differs from Unit I in its absence of ice-rafted dropstones, higher clay mineral content, and lack of turbidites. A significant change in microfossil content occurs at 330-340 mbsf. Siliceous fossils are present only above this interval, locally in concentrations of up to $10 \%$. In subsequent sections, we will see that the largest change in physical properties and log responses at Site 646 occurs at 336-340 mbsf. Based on seismic stratigraphic evidence, the sediments of Unit II are interpreted as drift deposits deposited during the major phase of drift construction of Eirik Ridge (Srivastava, Arthur, et al., 1987b).

\section{POROSITY}

At Site 646, porosity variation as a function of depth was determined from pycnometer measurements on $10-\mathrm{cm}^{3}$ core samples and from the medium induction resistivity log. The pycnometer porosities are much more accurate ( \pm 1 porosity unit) than resistivity-log porosities ( \pm 15 porosity units absolute accuracy, \pm 0.5 porosity units relative accuracy of nearby measurements). The resistivity-log porosities are more continuous and more representative of overall formation porosities. In this study, porosities are usually expressed in porosity units $(0 \%-100 \%$ by volume), but calculations involving porosity use fractional porosity $(\phi, 0-1.0)$.

The pycnometer porosities were measured for undisturbed core samples or, when necessary, drilling biscuits. Core porosities were corrected for salinity according to Hamilton's method (1971). Because laboratory pressures are much less than in-situ stress, we corrected for post-coring rebound, or expansion, of the cores. Based on an experimentally determined curve of porosity rebound as a function of depth in terrigenous sediments (Hamilton, 1976a), the porosity measurements for Site 646 were corrected to the in-situ condition (Fig. 1). This rebound correction increases from 0 at the seafloor to 8.4 porosity units at the bottom of the hole. Busch (this volume) applies a rebound correction to porosities from Site 646 based on overburden pressure (Hamilton, 1976a), rather than depth; the two techniques yield nearly identical corrections at this site. Note that this correction is only approximate, however, because experimental data on the effects of rebound are few and terrigenous sediments may vary substantially in their mechanical properties. Diagenetic lithification reduces rebound; cherts and chalks can depart substantially from empirical curves of rebound vs. depth (Goldberg et al., 1987). In contrast, diagenesis is minor at Site 646, and lithification increases gradually through mechanical compaction. Thus, the empirical curve appears to be appropriate for rebound correction at this site.

Conversion of a resistivity log to porosity is subject to even greater uncertainties. The relationship of formation resistivity to porosity for clean sands (pure quartz) is well known from Archie's equation (1942),

$$
S_{w}^{n}=\frac{a R_{w}}{\phi^{m} R_{t}}
$$

where $S_{w}$ is water saturation (equal to 1 for these hydrocarbonfree sediments), $n$ is an exponent (usually assumed to be 2), $R_{w}$ is resistivity of the formation water, $\phi$ is fractional porosity, $R_{t}$ is measured formation resistivity, and both $a$ and $m$ are constants, depending on lithology. We calculated porosity using the Humble formula (Winsauer et al., 1952), which assumes that $a=$ 0.62 and $m=2.15$. Alternative values ( $a=0.88$ and $m=1.37$ ) for weakly cemented detrital rocks with porosities of $25 \%$ to $45 \%$ (Keller, 1982) were examined, but the resulting calculated porosities are too low (by 4 to 6 porosity units) to be reconciled with pycnometer measurements. Further, this reduction in porosity caused us to overestimate the bound water and, therefore, the clay mineral percentage, as discussed in the next section.

Archie's equation (1942) is generally applicable only to formations having no clay minerals, because measured resistivity includes contributions from both free water in pores and bound water in clays. More sophisticated models (Waxman and Smits, 1968; Clavier et al., 1977; Pape and Worthington, 1983) are needed to account for the clay effect at the low porosities usually encountered in the petroleum industry. However, for the high porosities at Site 646 , the effect of ignoring the resistivity of clays was that we overestimated porosity by only about 0.1 to 0.5 porosity units.

The resistivity of formation water was estimated by using the known relationship of $R_{w}$ to temperature and salinity (Keller, 1982). Measurements of interstitial-water salinities at this site (Srivastava, Arthur, et al., 1987b) were interpolated for estimating salinity throughout the logged interval. Although such measurements were few, the effect on $R_{w}$ of observed salinity variations is small, and a log of salinity indicator ratio from the gamma spectroscopy tool (Srivastava, Arthur, et al., 1987b) shows that no zones of substantially different salinity were missed by the interstitial-water sampling. The geothermal gradient at Site 646 is $0.094^{\circ} \mathrm{C} / \mathrm{m}$, based on sub-bottom temperatures measured during coring (Louden et al., this volume). However, the temperature of formation water near the borehole during logging was much less than equilibrium sub-bottom temperatures, because a substantial amount of seawater (at approximately $0^{\circ} \mathrm{C}$ ) was pumped downhole during drilling and just before logging. No temperature logging was undertaken at this site. For the estimation of $R_{w}$ vs. depth, we assumed a geothermal gradient of one-fourth the equilibrium value, with temperatures ranging from $0^{\circ} \mathrm{C}$ at the base of the pipe (location of maximum fluid circulation) to $18.4^{\circ} \mathrm{C}$ at the bottom of the hole. These estimates of temperature and salinity effects on $R_{w}$ result in the porosity log in Figure 1. To illustrate the sensitivity of calculated porosity to assumed temperature, the extreme assumptions of equilibrium temperature profile and completely cooled hole $\left(0^{\circ} \mathrm{C}\right)$ yield porosity values near the bottom of the hole that are about 15 porosity units too low and 10 porosity units too high, compared with rebound-corrected laboratory values.

Despite the uncertainties in determining in-situ porosities from pycnometer and resistivity log data, the two curves show remarkable agreement (Fig. 1). Further, both curves are similar to the average porosity vs. depth trend of Hamilton (1976a) for terrigenous sediments, particularly below $340 \mathrm{mbsf}$. Both curves indicate that porosity decreases suddenly by about 7 porosity units at 340 mbsf. In the next section, we will examine the mineralogical cause of this decrease, as well as further tests of the accuracy of the porosity curves.

The rebound-corrected pycnometer porosities exhibit a much higher variance than $\log$ porosities. This difference probably is not solely attributed to pycnometer measurement errors, be- 


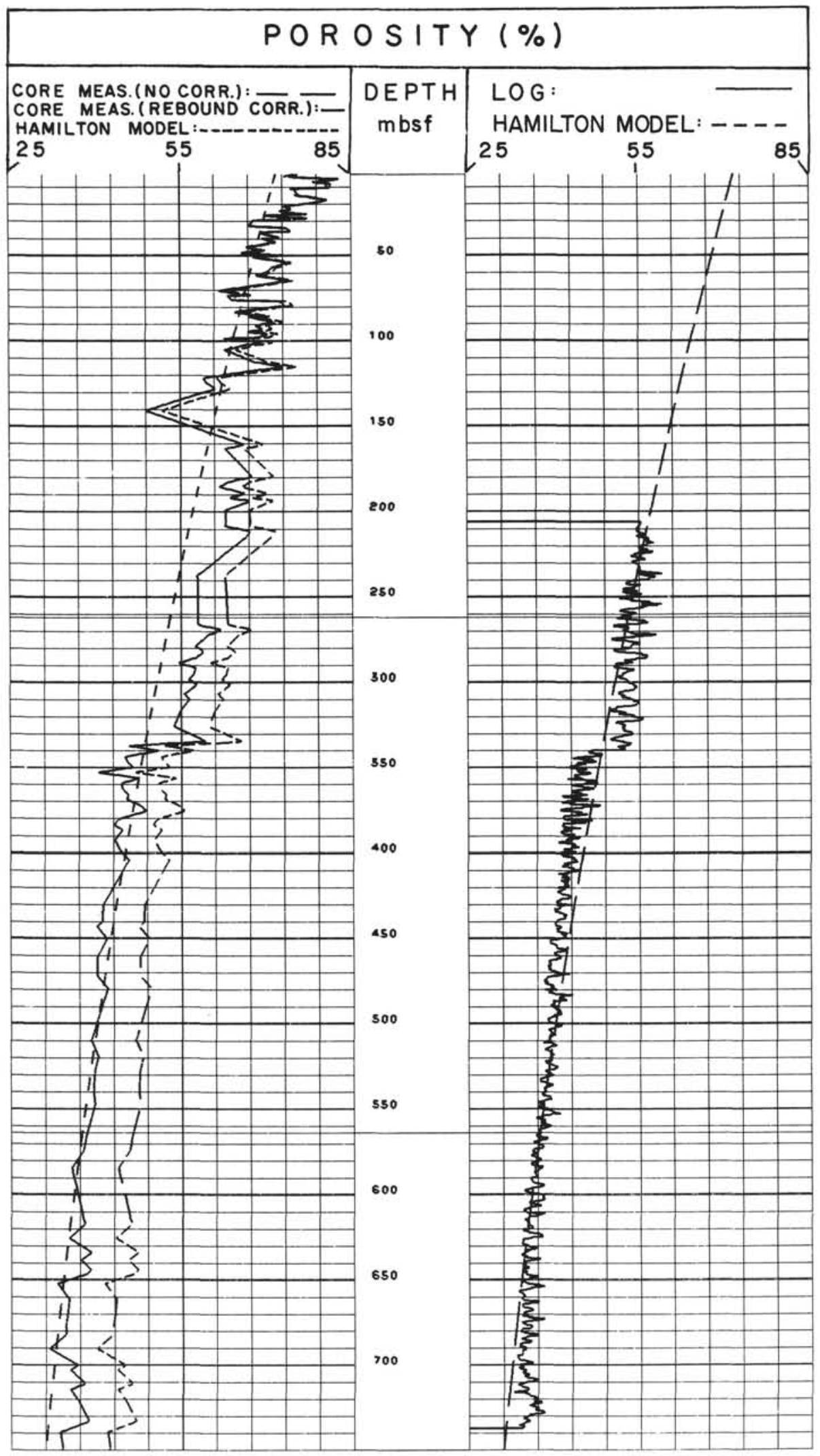

Figure 1. Porosity as a function of depth at Site 646. Log (right) is calculated from resistivity, as described in text. Laboratory measurements on core samples (left) are shown before and after rebound correction to in-situ pressures; linear interpolation is used between discrete core measurements. Note the good agreement between laboratory and log porosities, except for slightly higher laboratory porosities in the interval 206-340 mbsf. Hamilton's empirical curve of porosity vs. depth (1976a) agrees well with both data sets. 
cause porosity and density measurements for the same samples correlate well (Srivastava, Arthur, et al., 1987b). Instead, the greater variance in laboratory measurements probably results from the $10^{5}$ difference in volumes measured. Pycnometer porosity samples are approximately $10 \mathrm{~cm}^{3}$, whereas the medium induction resistivity log averages porosity variations of approximately a meter thickness.

\section{MINERALOGY}

Continuous logs of abundance of the major minerals at Site 646 as a function of depth could prove useful for sedimentological interpretation. In this analysis, such logs have a different application: the mineralogy of the sediments can affect porosity, density, and acoustic velocity.

One can estimate mineral abundances by matrix inversion of selected logs, given a knowledge of both matrix responses and the types of minerals present. Doveton (1986) described this technique and its associated assumptions and potential errors. $\mathrm{X}$-ray diffraction (XRD) data are ideal for constraining the inversion by specifying types of minerals present. However, equipment breakdown precluded shipboard XRD measurements for Site 646, and only two general XRD observations were available in time for this analysis: (1) clay mineral composition is relatively constant throughout the well, and (2) feldspar is much more common than was estimated from smear slides, perhaps because feldspar is easily mistaken for quartz in smear slides. Detailed XRD data for Site 646 were not available at the time of our analysis; however, Cremer and LaTouche (this volume) do present these data. Comparison of their results with ours can provide the reader with an independent test of the accuracy of our inversion.

From smear-slide estimates of mineral percentage, the dominant minerals present at Site 646 are clay, quartz, calcite (detrital and calcareous microfossils), and potassium feldspar. Biogenic opal (diatoms, radiolarians, and sponge spicules), pyrite, and glauconite also are present in concentrations averaging less than $1 \mathrm{wt} \%$, and only rarely up to $10 \mathrm{wt} \%$; these trace minerals can be ignored in the mineralogy inversion. However, the logs used in our inversion are incapable of distinguishing quartz from plagioclase, or calcite from biogenic opal. Thus, we solve for clay, quartz plus plagioclase, calcite plus opal, and potassium feldspar.

We found three logs most useful for the inversion: bound water, potassium, and uranium/thorium ratio. The neutron log, which measures total hydrogen concentration, gives the sum of both free water in pores and bound water in clays. Because porosity has already been determined from resistivity (Fig. 1), it can be subtracted from the neutron log to yield an estimate of bound water. The resistivity $\log$, on which the porosity $\log$ is based, also responds to bound water, but this effect is minor at the high porosities considered here. Potassium $(\%)$, thorium (ppm), and uranium (ppm) are determined by the spectral gamma ray tool, through inversion of the energy spectrum of natural gamma radiation (Fertl, 1979). Uranium/thorium ratio proved useful as an indicator of biogenous components, because the ratio is near zero for unrecrystalized carbonates and opal, yet high and similar in magnitude for quartz, feldspar, and clay. For the inversion, this ratio was rescaled to 0.3 - uranium/thorium; this modified ratio has a matrix value near zero for quartz, feldspar, and clay and near one for calcite and opal.

Because the inversion did not need to solve for porosity, the bound water and potassium logs used in the inversion should be corrected for dilution by porosity. For example, the raw potassium log from Site 646 shows a gradual increase in potassium with depth (Srivastava, Arthur, et al., 1987b), which is largely caused by gradual decrease in porosity (increase in total rock volume) with depth, rather than a change in mineralogy. Con- version of potassium and bound-water logs to a porosity-free basis was accomplished by dividing both logs by $1-\phi$, based on the resistivity-log porosity. No such correction is needed for the uranium/thorium ratio because the virtual absence of uranium and thorium from pore water makes this ratio independent of porosity. The three logs used in the inversion are shown in Figure 2.

Several logs were not used in the inversion. Sonic logs are used to determine both porosity and mineralogy in the oil industry. However, the relationship of velocity to porosity is much less reliably known for porosities above $20 \%$ than for the lower porosities commonly encountered in the oil industry, as discussed in a subsequent section. The gamma ray log is often used in the oil industry to determine clay mineral abundance. However, both potassium feldspar and clay can potentially affect total gamma radiation; thus, for our analysis we found it more fruitful to use elemental abundances from the spectral gamma tool, instead of total gamma response. The quality of logs produced by the the gamma spectroscopy tool was a major disappointment. Even after substantial reprocessing, only the hydrogen and chlorine logs from this tool appear reliable. The hydrogen log agrees with the neutron log and thus adds nothing to an inversion. Iron, silicon, calcium, and sulfur logs are less reliable because of drift in the spectrum width during data collection.

The logs of bound-water percentage $\left(\phi_{b}\right)$, potassium $(K)$ and uranium/thorium ratio (U/Th) were inverted for mineralogy at every openhole log depth, based on the equations:

$$
\begin{aligned}
\phi_{b} & =0 \times \mathrm{FELD}+0 \times \mathrm{SiO}_{2}+0 \times \mathrm{CaCO}_{3}+45 \times \mathrm{CLAY}, \\
\mathrm{K} & =15 \times \mathrm{FELD}+0 \times \mathrm{SiO}_{2}+0 \times \mathrm{CaCO}_{3}+2.7 \times \mathrm{CLAY}, \\
0.3-\mathrm{U} / \mathrm{Th}= & 0 \times \mathrm{FELD}+0 \times \mathrm{SiO}_{2}+1 \times \mathrm{CaCO}_{3}+0 \times \mathrm{CLAY} .
\end{aligned}
$$

Here, "FELD" is potassium feldspar, with well-known matrix responses (e.g., Serra, 1987). " $\mathrm{SiO}_{2}$ " is actually the sum of quartz and plagioclase, which have nearly identical and wellknown matrix responses (e.g., Serra, 1987) for the three logs used. Similarly, " $\mathrm{CaCO}_{3}$ " is actually the sum of calcium carbonate and opal, above the 340 -mbsf first occurrence of opal in cores.

Calcium carbonate $\left(\mathrm{CaCO}_{3}\right)$ includes detrital carbonate and biogenic nannoplankton and foraminifers. From smear slides we know that most of the calcite in Unit II is nannoplankton tests. The U/Th ratio of this biogenous, unrecrystallized calcite is apparently low, in contrast to most carbonates on continents that have gained substantial uranium during diagenesis. Further, the very low U/Th ratio of this calcite contrasts with fortuitously similar and much higher U/Th ratios of feldspar, quartz, and clay. The usefulness of the U/Th ratio in these sediments as a calcite indicator ratio is suggested further by two observations: (1) the U/Th ratio usually exhibits a strong positive correlation with organic percentage (Fertl, 1979), and (2) organic content shows an inverse correlation with calcite at Site 646 (Srivastava, Arthur, et al., 1987b). Because the U/Th ratio approaches zero for high calcite content, the accuracy of the estimated calcite abundance is greater at low calcite abundances than at high values. Based on the abundance of calcite in smear slides and geochemical analyses for Site 646, we assumed that the lowest observed values of the U/Th ratio correspond to about $35 \%$ calcite; thus, a matrix value of 1 for $0.3-\mathrm{U} / \mathrm{Th}$ was used.

"CLAY" in the inversion equation is the total content of all clay minerals. Preliminary XRD data indicated that the mix of clay mineral compositions is approximately constant throughout Site 646 (Srivastava, Arthur, et al., 1987b), but the relative abundances of different clay types were not specified. More recent XRD data detect some variation of clay mineralogy as a 


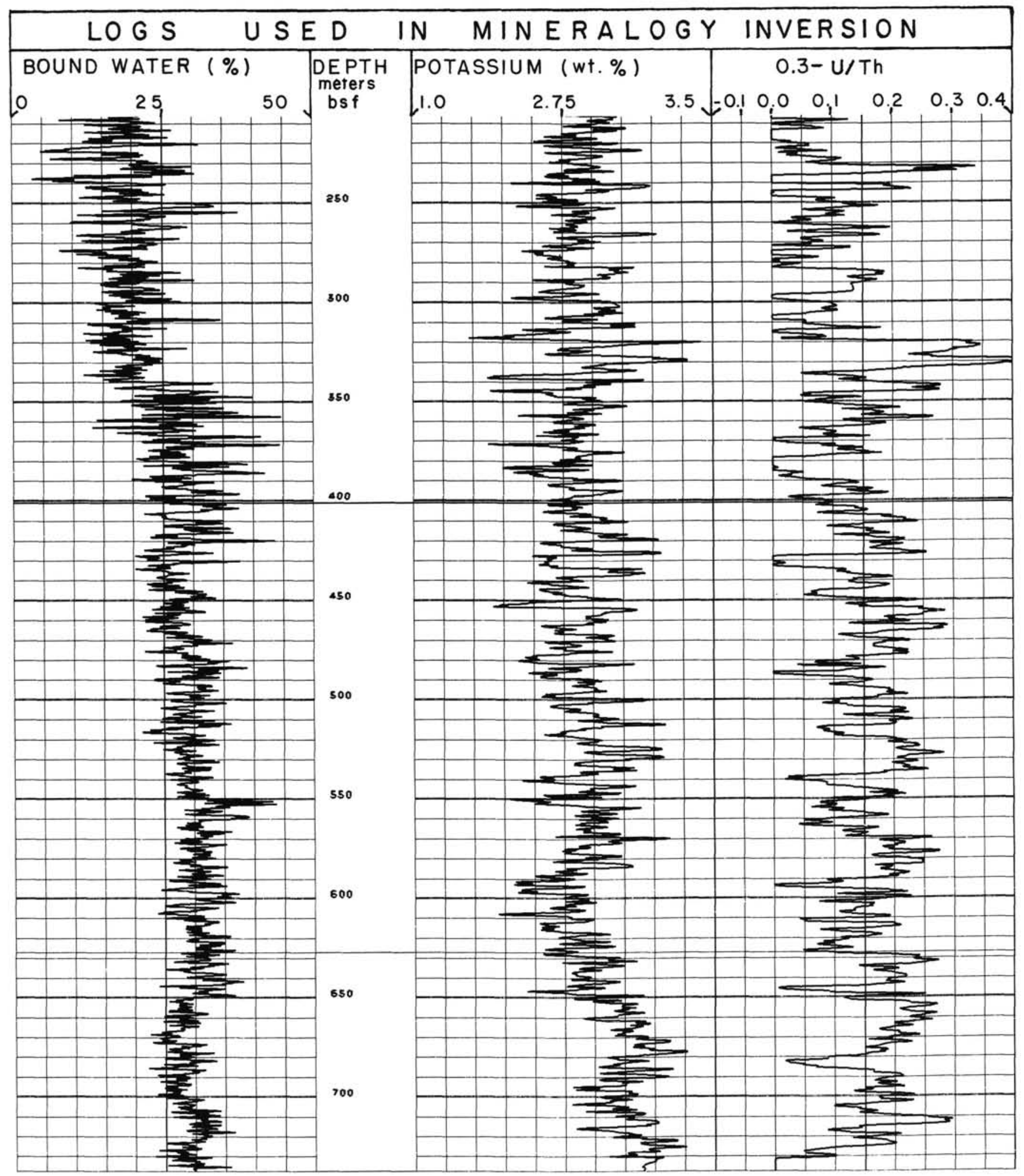

Figure 2. Three logs used in a matrix inversion to determine mineralogy (Fig. 3) at Site 646. Bound water (from neutron and porosity logs) and potassium (from spectral gamma ray tool) are on a porosity-free basis. Uranium/thorium log is from spectral gamma ray tool.

function of depth and indicate that the dominant clay minerals are montmorillonite and illite, with substantial chlorite and subsidiary kaolinite present (Cremer and LaTouche, this volume). Because the potassium content of clays is geographically somewhat variable, we determined empirically appropriate matrix values $\left(\phi_{b}=0.45\right.$ and $\left.\mathrm{K}=2.7\right)$ for total clay at Site 646 from a crossplot of $\phi_{b}$ vs K. These values suggest that the clay mineralogy is approximately $30 \%$ to $75 \%$ illite, based on the published (Serra, 1987) range of potassium contents for illite. The clay mineralogy studies of Cremer and LaTouche (this volume) indicate $25 \%$ 
to $35 \%$ illite. Although ODP does have other logs with good potential for clay typing, the logs available from Site 646 do not appear to permit calculation of the subtle variations of clay type as a function of depth.

Lacking detailed XRD data at the time of our analysis, we used smear slides to test the accuracy of our calculated mineral percentages. Smear slides proved useful for sedimentological description of cores, and the 291 smear slides from Site 646 constitute by far the most complete data set of independent estimates of mineral abundances. However, testing log mineralogy with smear slides has several weaknesses. First, the estimation of mineral abundance from smear slides is quite qualitative. For example, an abundance of small mineral grains (e.g., nannofossils) can dominate a smear slide but be volumetrically smaller than a single sand-sized quartz grain. Second, the 291 smear slides are far from uniformly distributed in depth; $51 \%$ are from the upper $206 \mathrm{~m}$ for which no log inversion was undertaken, and 10- to $15-\mathrm{m}$ gaps without smear-slide data are frequent. Third, each smear slide represents less than $1 \mathrm{~g}$ of material from a $1-\mathrm{cm}$ horizon. Even adjacent smear slides can vary dramatically in estimated mineral percentages, and it is not possible to estimate how representative a sample is. To cope with this high variance, we used a 10-sample running average, with a weighting three times as high for samples identified from a locally dominant lithology as for a locally minor lithology. This smoothing filter should reveal the major mineralogical variations downhole, unobscured by the undersampled fine-scale variations that dominate the raw data. Thus, we expect that a reliable log inversion should give a general match to major ( $>50$ m) peaks and troughs in smear-slide mineralogy, although more fine-scaled structure should be present in the logs.

Figure 3 overlays inversion-based log mineralogy with smoothed mineralogy from smear slides. In general, the fit is better than $\mathrm{migh}^{t}$ have been expected, considering the uncertainties in both techniques. For clay abundance, the two techniques often agree within $5 \%$. Both techniques indicate a change from about $60 \%$ to $40 \%$ clay near $350 \mathrm{mbsf}$, although there is a $20-\mathrm{m}$ discrepancy in depth of this change. The logs probably are more accurate for indicating this depth, which corresponds to the major porosity decrease evident in both pycnometer analyses and the porosity $\log$ at 336 mbsf. An apparent clay mineral peak at $300 \mathrm{mbsf}$ is not seen in logs, yet it is difficult to see how such a peak (if real) could not have affected the log of bound water. Between $\sim 550$ and $660 \mathrm{mbsf}$, the smear slides indicate $10 \%$ lower clay minerals than is indicated in the logs. Possible explanations are (1) smearslide studies have underestimated clay abundance, (2) a change in clay composition occurs, to a dominance of clay minerals with higher bound water (e.g., montmorillonite), or (3) bound water is overestimated, because the true porosity in this interval is about 5 porosity units higher than indicated by both the porosity log and pycnometer data.

The sudden decrease in porosity with depth at $336-340 \mathrm{mbsf}$ (Fig. 1) is associated with a substantial increase in clay minerals, but it is not caused by this increase. At depths of less than 1000 to 2000 mbsf, higher clay content normally causes higher porosity, because of the inefficient packing of clay minerals (Hamilton and Bachman, 1982). A correlation between small-scale changes in porosity and clay abundance changes is evident in most of Site 646 . The increased porosity is probably caused by the sudden absence of siliceous microfossils at this depth (Jarrard and Arthur, this volume). Alhough these microfossils are present in volumetrically small amounts above $336 \mathrm{mbsf}$, their effect on porosity can be dramatic because of their high intragranular porosity.

The general agreement of smear slides and logs in estimated abundances of clay is evidence for the accuracy of the porosity $\log$. This is particularly true in the upper portion of the section, with high porosity. For example, if the true porosity in the interval above 340 mbsf were 5 porosity units higher than the log values (as suggested by pycnometer data), then the estimated amounts of bound water and thus of clays would be too high by $20 \%$, because $\phi_{b}=(\phi$ neutron $-\phi /(1-\phi)$. Clearly, this magnitude of discrepancy is not present.

The log of quartz plus plagioclase agrees well with smearslide estimates of quartz from 206 mbsf to 500 mbsf, but is lower by $15 \%$ to $20 \%$ of total rock volume in the interval 520 to 660 mbsf. The potassium feldspar log is always higher by $5 \%$ to $10 \%$ of total rock volume than total feldspar from smear slides. Preliminary XRD data indicated that total feldspar (potassium feldspar plus plagioclase) may have been seriously underestimated in smear slides, because of difficulty in distinguishing feldspar from quartz (Srivastava, Arthur, et al., 1987b). The more recent and comprehensive XRD analyses of Cremer and LaTouche (this volume) confirm that feldspar is more abundant than quartz. Although Cremer and LaTouche indicate that the feldspar is primarily calcisodic, they do not give the proportions of calcisodic and potassium feldspar. A more appropriate comparison of smear slides to log mineralogy thus is total feldspar plus quartz. Such a comparison (Fig. 4) again shows the reasonable agreement above $500 \mathrm{~m}$ and the disagreement in the interval from 520 to 660 mbsf.

Similarly, calcite abundances show general agreement above $500 \mathrm{mbsf}$ and disagreement in the interval at 520-590 mbsf. Unlike clay and quartz curves, the calcite curve exhibits much more low-frequency variation on which to base a comparison. Both the logs and smear slides indicate a peak at $230 \mathrm{mbsf}$, a trough at 270-310 mbsf, a peak at $320-360 \mathrm{mbsf}$, a trough at $380 \mathrm{mbsf}$, a peak at $450-460 \mathrm{mbsf}$, a peak at $650-720 \mathrm{mbsf}$, and a trough at the bottom of the hole. However, other data are available on calcite abundance, which both complicate this simple character match and provide a somewhat discouraging test of the accuracy of smear-slide mineral abundances.

Shipboard analysis of calcium carbonate abundance was conducted using two techniques: the carbonate bomb and combustion of dried sediment (Srivastava, Arthur, et al., 1987b). Combining data from both techniques, 268 analyses are available from cores from Hole $646 \mathrm{~B}$, with $38 \%$ of them in the log interval below 206 mbsf (Fig. 5). Sampling was most dense in the top $100 \mathrm{~m}$, the same interval for which smear slide analyses were most abundant. Yet in this interval, smear slides and calcite analyses show only fair agreement (Fig. 5), and smear slides overestimate calcite abundance by at least a factor of two. Only one other interval has dense calcite analyses: the interval at 340400 mbsf. Again, in this interval, smear slides greatly overestimate calcite abundance. Overall, a general similarity of most but not all major peaks and troughs can be seen (Fig. 5). The between-sample spacing for calcite analyses is even greater than for smear slides, and no smoothing or weighting was applied to the former. Consequently, detailed testing of the accuracy of our calcite log is not possible. However, it is apparent that calibration of $\mathrm{U} / \mathrm{Th}$ matrix responses with calcite analyses would have been preferable to calibration with smear slides, because both the logs and smear slides overestimate calcite abundance somewhat. This overestimation does not affect the downhole changes in relative abundance indicated by the logs. In general, the agreement of our calcite plus opal log with calcite analyses is only fair.

Summarizing the above comparisons, we conclude that the calculated mineral abundances from logs have an average absolute accuracy of about $10 \%$. The relative accuracy of changes indicated by logs on a vertical scale of $<50 \mathrm{~m}$ may be substantially higher, as it is controlled by observed log changes rather than accuracy of assumed matrix responses. We consider the calculated mineral abundances to be the least reliable result of 


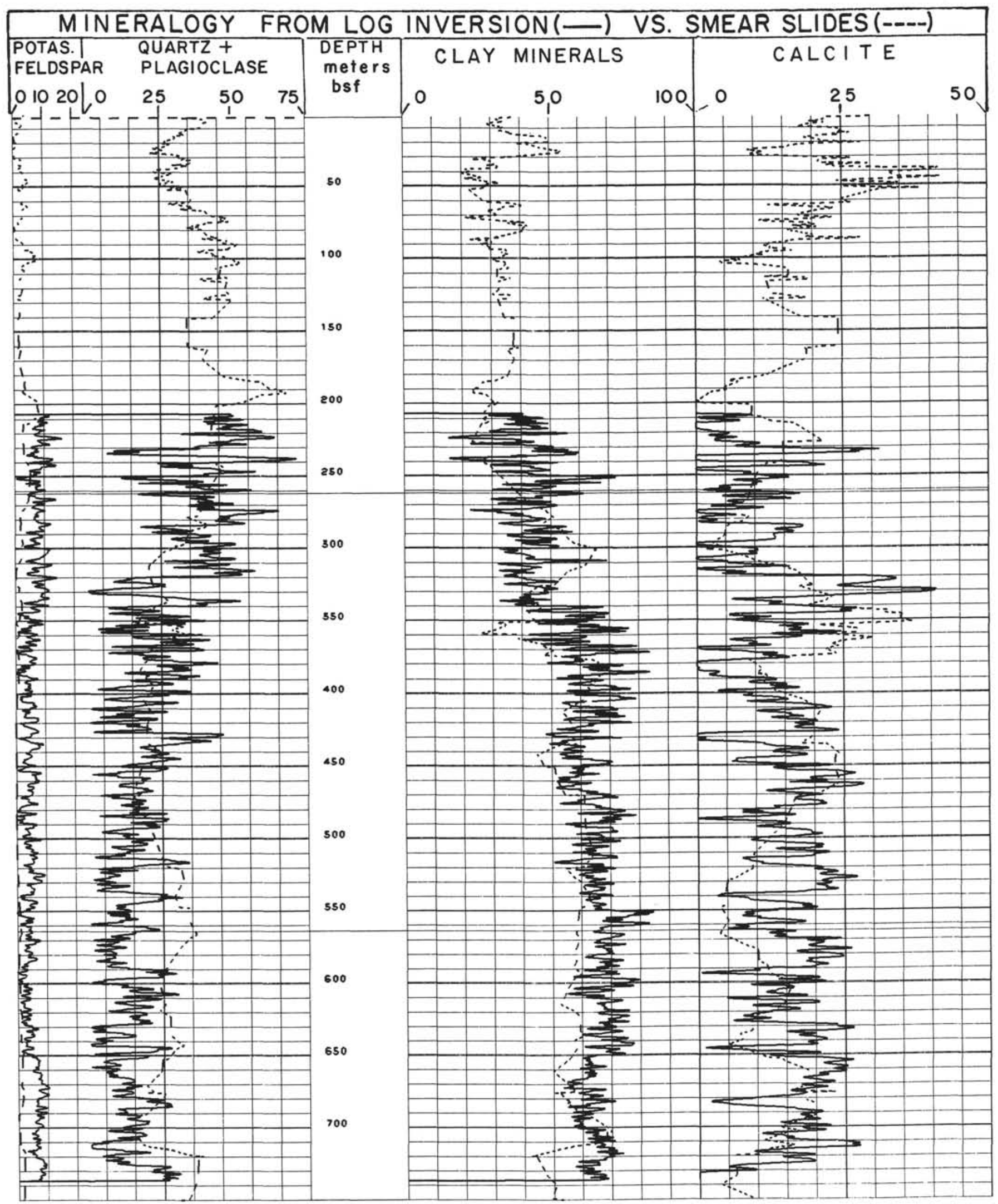

Figure 3. Comparison of computed mineral abundances (porosity-free) from log inversion with those from smear-slide descriptions. Ten-point smoothing is applied to discrete smear-slide estimates. 


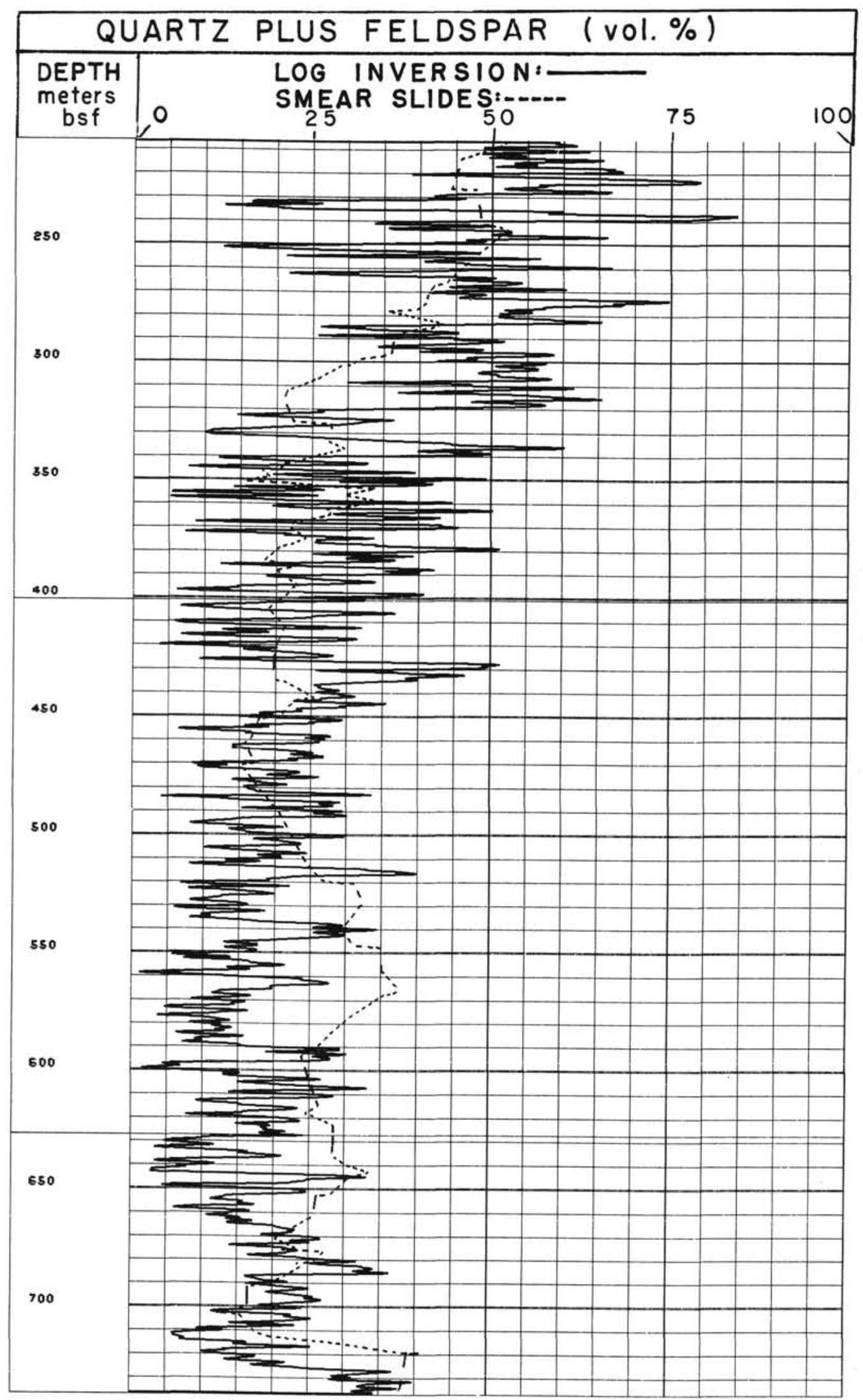

Figure 4. Comparison of computed total abundances of quartz plus feldspar (porosity-free) from log inversion with those from smear-slide descriptions. 


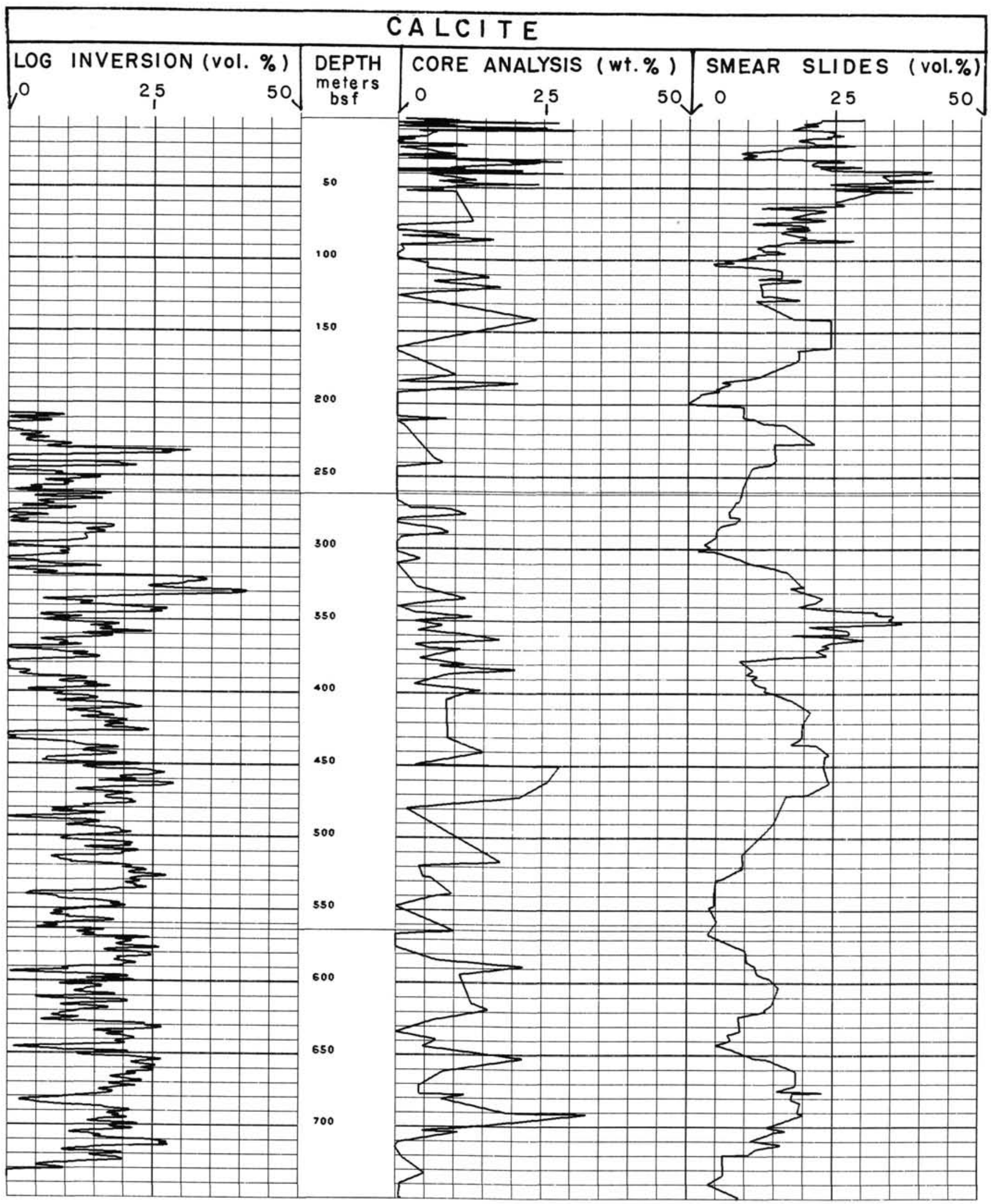

Figure 5. Comparison of three estimates of calcite abundance (porosity-free) variations at Site 646. Linear interpolation is used between discrete core analyses, as well as between smoothed discrete smear-slide measurements. Core analyses are considered to be the most accurate, although probably nonrepresentative because of widely spaced samples. Note the fair match of broad peaks and troughs among the three techniques, but lack of a detailed match in intervals with most data $(0-50 \mathrm{mbsf}$ and $340-400 \mathrm{mbsf})$. Note also the general overestimation of calcite percentage by the log and smear slides. 
this study, because the neutron and U/Th logs have low signalto-noise ratios and because of uncertainties in the U/Th matrix responses. Fortunately, we shall see in subsequent sections that our density and velocity conclusions are relatively insensitive to uncertainties in mineralogy. Figure 6 shows a lithologic and mineralogic column based on the log inversion. Figure 7 details a $100-\mathrm{m}$ interval, bracketing the 340 mbsf porosity change and giving a better resolution of the fine-scaled mineralogic variations than is possible at the scale of Figure 6.

\section{BULK AND GRAIN DENSITIES}

Bulk density and apparent grain density of core samples were directly measured by pycnometer. Apparent grain density $\left(\rho_{m a}\right)$ was also determined by the indirect method of calculation from porosity $(\phi)$ and bulk density $\left(\rho_{b}\right)$, based on the equation,

$$
\rho_{b}=\phi \rho_{f}+(1-\phi) \rho_{m a}
$$

where $\rho_{f}$ is fluid density. One might expect the direct method to yield results that are more reliable and have a smaller variance than the indirect method, because the direct method requires fewer measurements. However, as seen in Figure 8, the indirect method yields substantially lower variance than the direct method. Further, the mean grain density for the indirect method is about $0.15 \mathrm{~g} / \mathrm{cm}^{3}$ less than for the direct method.

Grain density (or matrix density) can also be estimated from logs. No density logging was conducted at Site 646 . However, the calculated mineral percentages can be used to calculate mean apparent grain density at each horizon, using the well-known (e.g., Serra, 1987) grain densities (in $\mathrm{g} / \mathrm{cm}^{3}$ ) of the component minerals:

$$
\rho \mathrm{CaCO}_{3}=2.71, \rho \mathrm{SiO}_{2}=2.65, \rho \mathrm{K} \text {-spar }=2.52 \text {, and } \rho \text { clay }=2.90 \text {, }
$$

where the clay is assumed to be a mix of illite, montmorillonite, and kaolinite with only minor chlorite. The resulting log of grain densities is shown in Figure 8.

When comparing the grain-density log with direct and indirect measurements of grain density on cores, it is evident that the variance of $\log$ values is substantially smaller than that of the core measurements. This phenomenon, similar to what was observed in porosity (Fig. 1), could also be attributed to the presence of fine-scaled variations that are smoothed by the averaging interval of the logs. However, it is difficult to reconcile the extreme grain densities with smear-slide evidence for the minerals present. For example, direct and indirect values as low as $2.49 \mathrm{~g} / \mathrm{cm}^{3}$ are lower than the grain densities of any likely minerals at this site, and occasional direct measurements above 3.22 $\mathrm{g} / \mathrm{cm}^{3}$ imply almost pure chlorite. More likely, the observed variance in grain densities from cores is at least partially attributable to measurement imprecision.

The average grain density from logs is much less than that from the direct pycnometer method and similar to that from the indirect pycnometer method. We cannot account for this difference. Above $340 \mathrm{mbsf}$, both types of data average $2.75 \mathrm{~g} / \mathrm{cm}^{3}$. Below $340 \mathrm{mbsf}$, both average about $2.80 \mathrm{~g} / \mathrm{cm}^{3}$, with the grain densities from logs slightly higher than those from the indirect pycnometer method. Dispersion prevents a precise determination of the depth of this transition in the pycnometer data. The change in grain densities at 340 mbsf results from the baseline shift in clay content (Figs. 3 and 7).

Pycnometer measurements of variation in bulk density at Site 646 (Fig. 9) exhibit a strong character similarity to porosity variations. In contrast, bulk-density variations are not as obviously similar in character to grain-density variations. These observations suggest that bulk-density changes at Site 646 are primarily caused by changes in porosity, not mineralogy. Of course, mineralogy may also affect density through mineralogic controls on grain size, but the first-order relationship is that porosity controls density.

Density measurements at laboratory pressures can be influenced by the same rebound effect that changes porosity. We determined rebound-corrected bulk densities from Equation 1, using rebound-corrected porosities and grain densities determined by the indirect pycnometer method (i.e., from bulk density and porosity at laboratory pressure). This density rebound correction increases with depth, from zero at the seafloor to about $0.16 \mathrm{~g} / \mathrm{cm}^{3}$ in the bottom $250 \mathrm{~m}$ of the hole.

A pseudodensity log (Fig. 9) was calculated from the graindensity (Fig. 8) and porosity (Fig. 1) logs, using Equation 1. This pseudodensity log exhibits smaller variance than the density measurements on discrete samples, presumably because it samples much larger volumes. Both measurement types can be used to detect a major increase in density at 336-340 mbsf, resulting partly from a downward increase in grain density (higher clay content), but primarily from the decrease in porosity. However, similar large changes in density suggested by the lab measurements at 200,400 , and 450 mbsf are not corroborated by the pseudodensity log. These three changes are largely attributable to single-density measurements; their importance is exaggerated by linear interpolation between widely spaced measurements.

Average densities from the pseudodensity log and reboundcorrected laboratory measurements agree well from 206 to 370 mbsf (Fig. 9). Below about 370 mbsf, the pseudodensity log has values about intermediate between uncorrected and reboundcorrected laboratory measurements. This discrepancy may indicate that the grain density of clays at Site 646 is slightly higher than the $2.9 \mathrm{~g} / \mathrm{cm}^{3}$ used to calculate the grain-density $\log$ of Figure 8. We assumed that chlorite was an insignificant component of these clays, whereas the more recent XRD data of Cremer and LaTouche (this volume) indicate that the clays are $15 \%$ to $25 \%$ chlorite. Thus, using a clay grain density of 3.0 would be more consistent with the XRD data and would remove the slight difference between pseudodensities and rebound-corrected laboratory densities. Such a subtle change would not make our $\log$ grain densities agree with direct pycnometer grain densities, rather than indirect ones. No revision of clay matrix density was undertaken, because the adjustment is small in comparison to the discrepancy between direct and indirect laboratory measurements of grain density.

An empirical trend of bulk density vs. depth for terrigenous sediments (Hamilton, 1976a) is also shown in Figure 9. This trend fits the pseudodensity log data reasonably well, although of course it does not predict the sudden increase in density at 340 mbsf. Rebound-corrected density measurements fit the density curve well from 0 to about 340 mbsf, with the exception of a density peak at $140 \mathrm{mbsf}$ and a trough at $212 \mathrm{mbsf}$, caused by one and two anomalous measurements, respectively. Below about 340 mbsf, the empirical trend fits the uncorrected density measurements better than the rebound-corrected measurements. Nevertheless, the latter are probably a better estimate of true density variations at Site 646 than the former. The $60 \%$ clay content below 340 mbsf at Site 646 is probably higher than in the regions Hamilton (1976a) used to establish his trend.

\section{VELOCITY}

The sonic velocity log at Site 646 is of excellent quality, with nearly identical velocities for short- and long-spaced logs. The short-spaced $\log$ is the difference between traveltimes for 2.4and 3.0-m source-receiver pairs; the long-spaced log uses 3.0and $3.6-\mathrm{m}$ pairs. In both cases, $P$-waves are determined from waveforms by a simple first-break criterion during data acquisition. The log used here (Fig. 10) is an average of these two mea- 

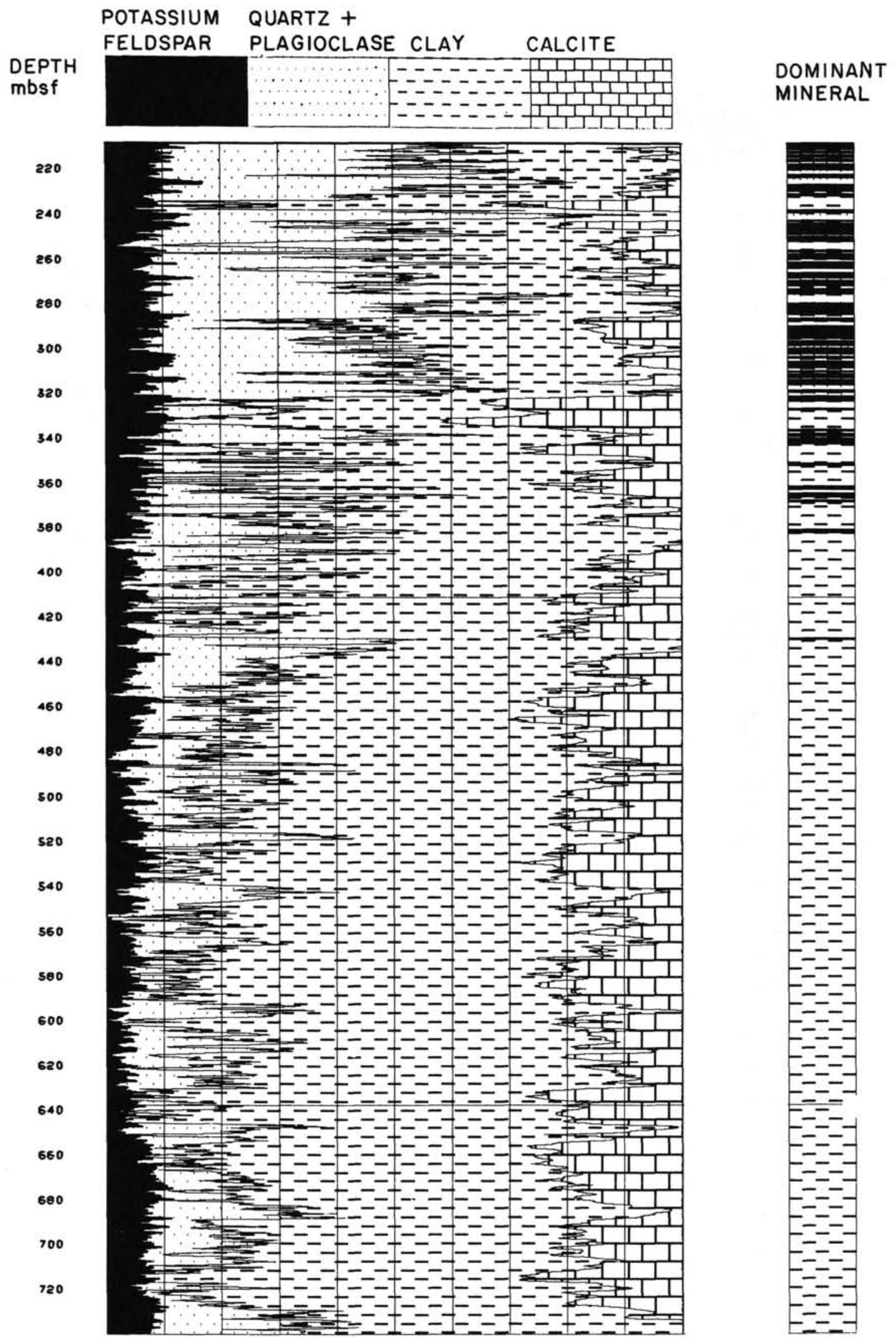

Figure 6. Mineralogical abundance variations (from Fig. 3) at Site 646, based on log inversion. 


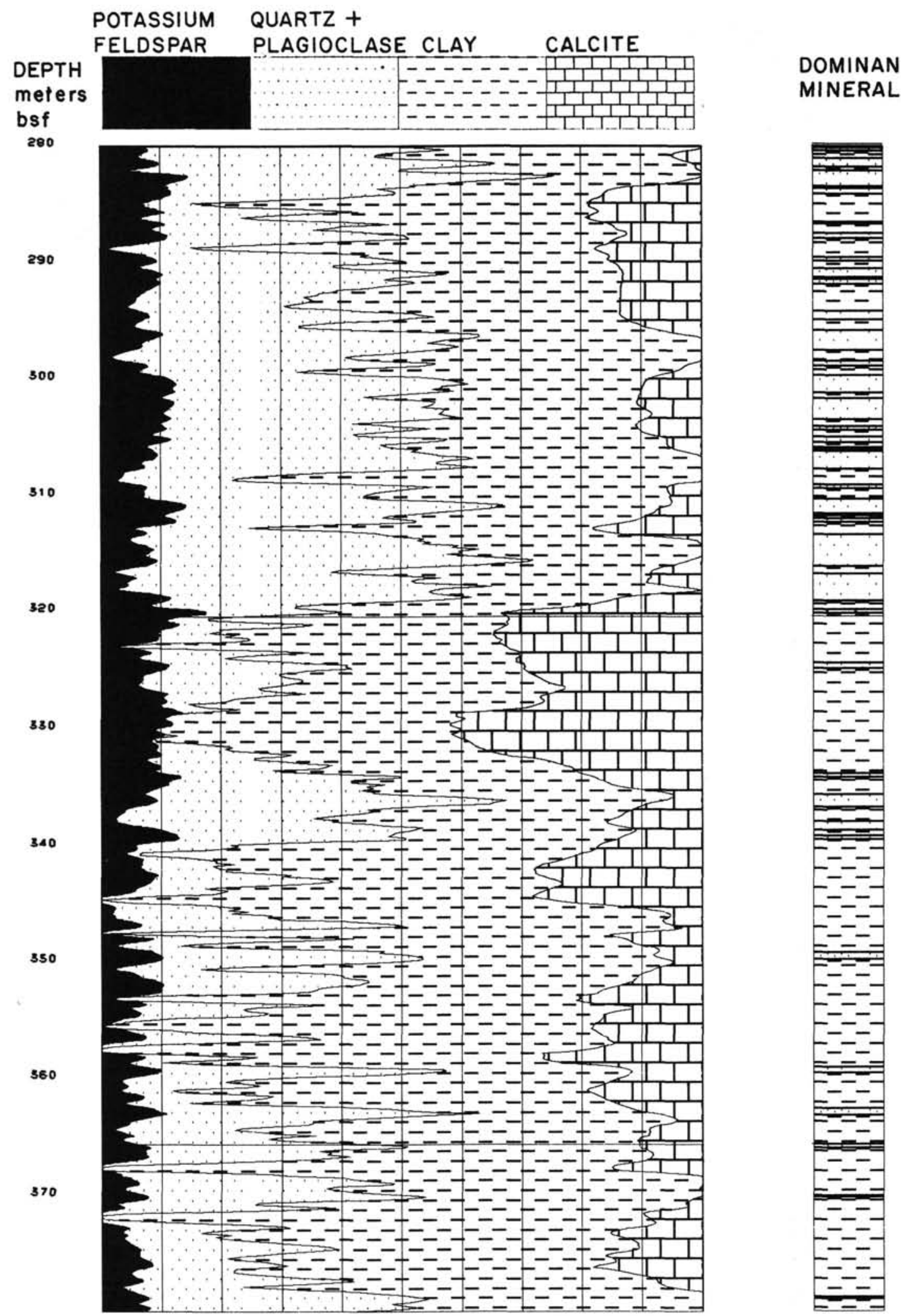

Figure 7. Expansion of a 100-m interval from Figure 6, to show computed mineralogical abundance variations across the $340 \mathrm{mbsf}$ porosity transition. Note the much higher quartz content and lower clay mineral content above $340 \mathrm{mbsf}$. 


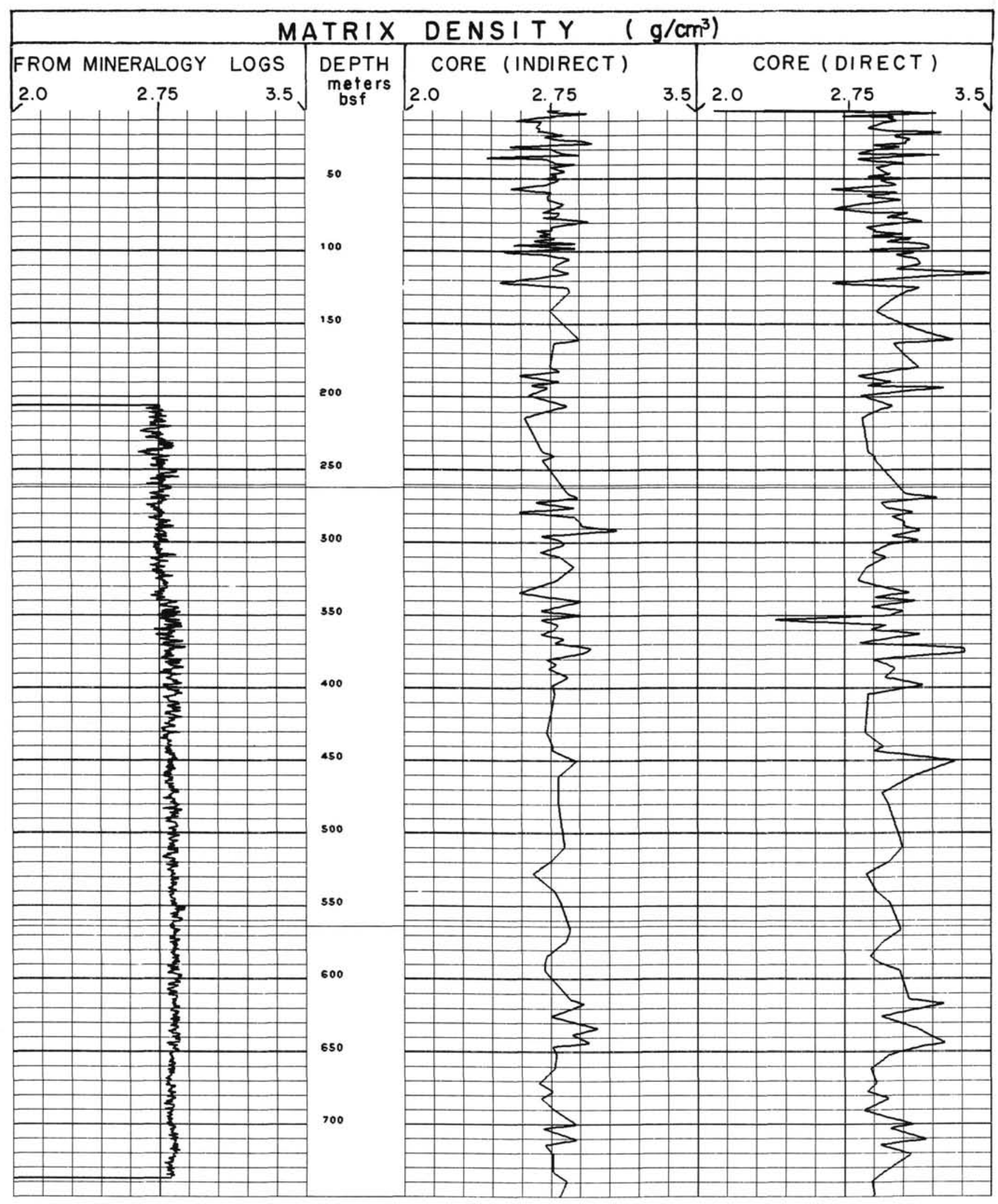

Figure 8. Comparison of three estimates of matrix (or grain) density at Site 646. Left: log based on combined grain densities of mineralogy logs. Right: two methods of calculating matrix density from pycnometer analyses of cores. Note that the indirect method shows smaller dispersion and an average value closer to log results than does the direct method. Note also the downhole increase in grain density at $340 \mathrm{mbsf}$ in data from both the log and the indirect method; this increase results from increased proportion of clay minerals. 


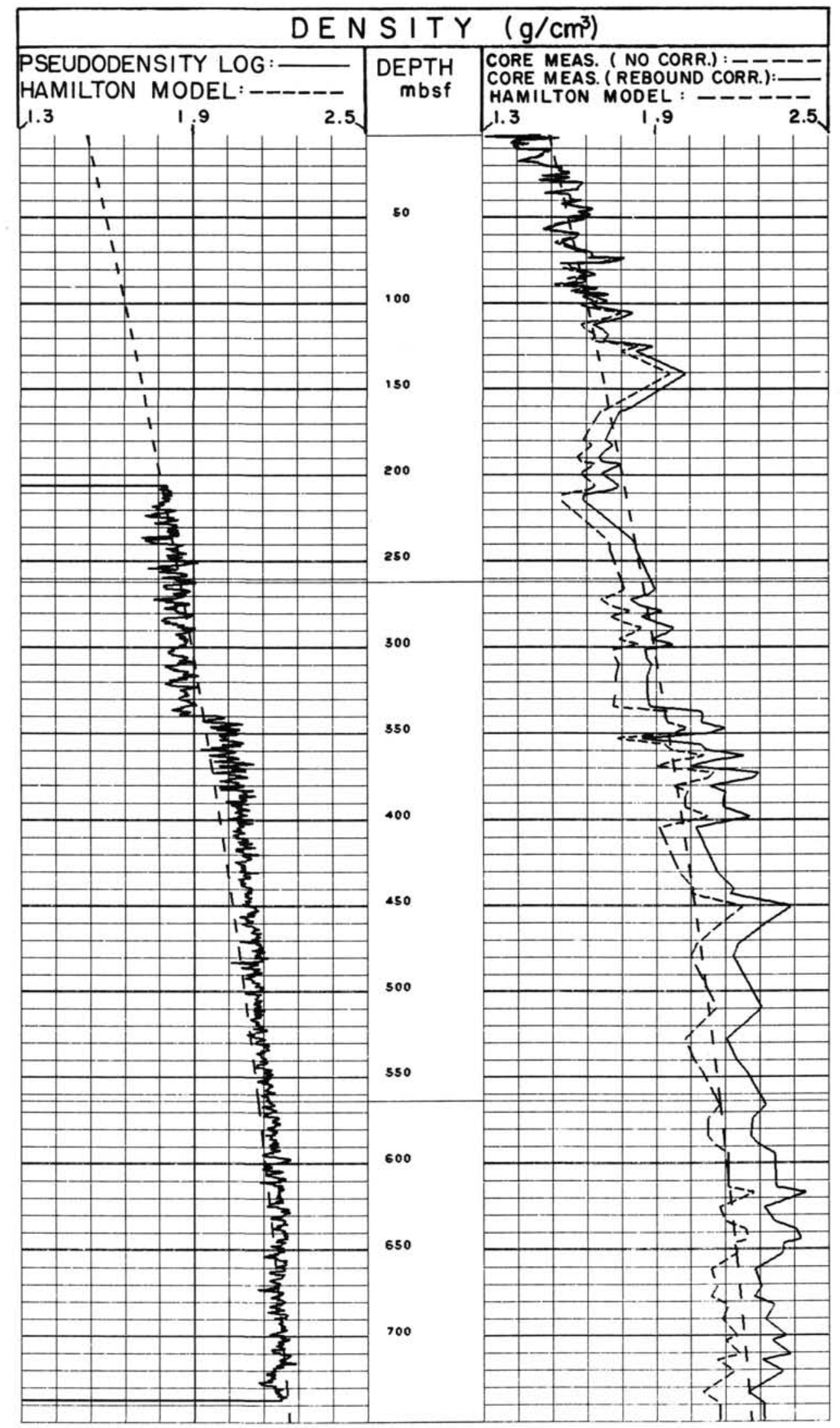

Figure 9. A. "Pseudodensity" log, calculated from porosity and grain-density logs. B. Laboratory measurements of bulk density, before and after correction for rebound. All data show general agreement with Hamilton's empirical density vs. depth curve (1976a) for terrigenous sediments. Note that rebound-corrected measurements have similar values to the log between 206 and $340 \mathrm{mbsf}$, but they are higher than the $\log$ by $0.05-0.10 \mathrm{~g} / \mathrm{cm}^{3}$ below $340 \mathrm{mbsf}$. 


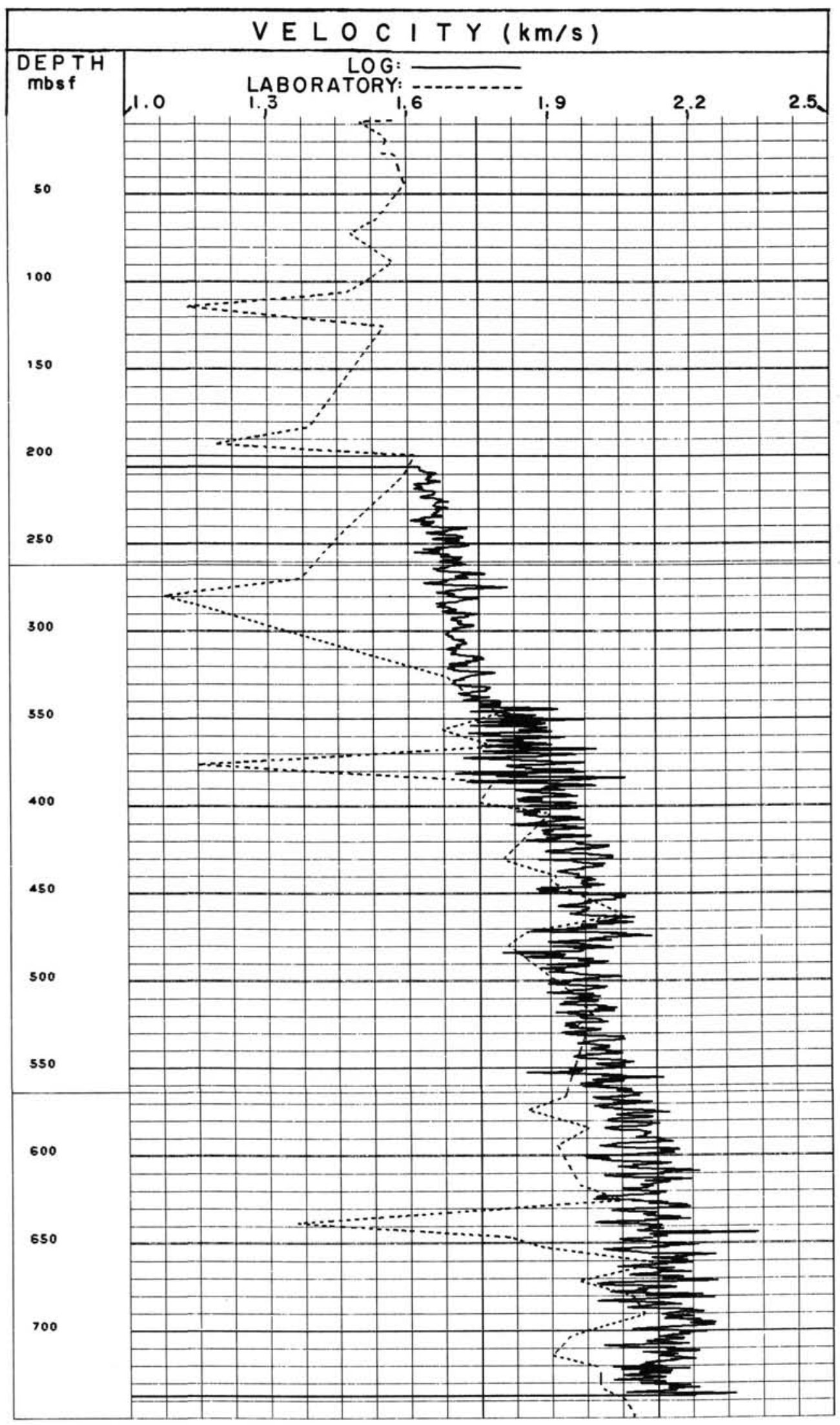

Figure 10. Comparison of compressional wave velocities from downhole logging with those from laboratory measurements on cores. Straight dashed line segments connect the widely spaced core measurements. Note that laboratory measurements yield velocities that are nearly always too low and occasionally much slower than water $(1.5 \mathrm{~km} / \mathrm{s})$. 
surements, reprocessed to remove rare cycle skips (Shipboard Scientific Party, 1987b).

We also determined a sonic velocity log by applying semblance analysis to sonic waveforms (Kimball and Marzetta, 1984; Goldberg and Gant, 1988). Comparison of the two logs indicates that (1) average velocities over a 3-m interval are virtually identical, (2) the semblance coefficient (a measure of waveform coherence) exhibits a cyclic variation reminiscent of that in the porosity and first-break velocity logs, (3) the semblance velocity log lacks this smoothly cyclic behavior, and (4) the first-break velocity log exhibits a better character match to the porosity log than the semblance velocity log. All these observations are consistent with the conclusion that both velocity logs are reliable, but that the first-break log has much higher vertical resolution. With the geometry of the Schlumberger long-spaced sonic tool, waveform analysis maximizes semblance of receivers with a 1.2$\mathrm{m}$ maximum spacing. In contrast, our processing of first-break data takes the difference in arrival times at receivers located 0.6 $\mathrm{m}$ apart, giving twice the vertical resolution. When log quality is poor to good, cycle skipping and differencing greatly increase errors for the first-break technique, and waveform analysis is superior. In contrast, at Site 646 velocity log quality is high enough to make waveform analysis unnecessary, and the higherresolution first-break $\log$ is used for Figure 10 and subsequent analyses.

Comparison of velocity (Fig. 10) with porosity (Fig. 1) logs shows a remarkably high correspondence of high-frequency character. In contrast, the velocity log exhibits little high-frequency similarity to the grain-density log of Figure 8 . Clearly, porosity variations are much more important than mineralogy variations for controlling velocity changes at Site 646 . The porosity variations appear to be caused primarily by changes in grain-size distribution of quartz, rather than mineralogic changes (e.g., quartz/ clay or quartz/nannoplankton ratio), because mineralogical porosity changes would cause a correlation between grain density and velocity. However, the grain-density $\log$ is affected by the noise in all three logs used in the mineralogy inversion, degrading the correlation with velocity. Further, Jarrard and Arthur (this volume) show that the gamma-ray log correlates with porosity, indicating that small-scale porosity variations are partially caused by variation in clay-mineral content. One clear case of a mineralogical effect on velocity is seen at 340 mbsf. At this depth, porosity decreases substantially (downward) and clay content doubles. Velocities increase by less than would be expected from the decrease in porosity, because the low matrix velocity of clay counteracts the porosity effect.

Velocities of 64 core samples (Fig. 10) were measured at atmospheric pressure on a Hamilton frame velocimeter (Srivastava, Arthur, et al., 1987a). Unlike porosity and density measurements, sampling density was lower in the uppermost part of the well than it was near the bottom, because of the difficulty of obtaining reliable velocity measurements for high-porosity, unconsolidated sediments. Nevertheless, most samples did yield apparently reliable velocities; the few excursions to very low velocities (Fig. 10) probably result from inadequate coupling between sample and transducer.

The measurements of core velocity are not representative of in-situ velocities. As with porosity and bulk density, rebound probably affects the measured velocities (Srivastava, Arthur, et al., 1987b). Laboratory velocities are consistently lower than insitu sonic velocities (Fig. 10). Rebound correction of these velocity measurements is less straightforward than rebound correction of density measurements, because the effect of rebound on bulk and shear moduli may be more complex than a simple porosity change and because most porosity and velocity measurements used different samples.
Laboratory velocity is plotted vs. porosity of the nearest sample in Figure 11. Obviously unreliable velocities (at 114, 183, 193, 270, 280, 376, and 638 mbsf in Fig. 10), much slower than water velocity, are omitted. Figure 11 also shows a contoured data density plot of the 3496 velocity and porosity log measurements. If the rebound effect on the laboratory velocity measurements is a simple porosity one, then the log and laboratory measurements should plot along the same curve. Of course, the laboratory measurements should and do extend to higher porosities than log measurements, both because of rebound and because no log measurements are available in the top $206 \mathrm{~m}$ of the hole. For porosities of $50 \%$ to $60 \%$, the laboratory measurements have a velocity/depth trend consistent with that of log measurements; too few laboratory measurements are available to detect a possible offset of trends for the two data sets. For porosities of less than $50 \%$, there are enough laboratory measurements to demonstrate a significant difference between the velocity/porosity relationships of log and laboratory data. Because the log data appear to be reliable and rebound-corrected porosities agree with $\log$ porosities (Fig. 1), this difference implies that porosity rebound alone cannot account for the observed discrepancy between laboratory and log velocities (Fig. 10). Thus, we have no reliable method of extrapolating the laboratory velocity measurements to in-situ conditions.

To determine velocity as a function of depth for the entire drilled section at Site 646, we cannot simply merge laboratory measurements above 206 mbsf with log measurements below that depth, for several reasons. First, some laboratory measurements are obviously unreliable (Fig. 10). Second, comparison of laboratory with log measurements below 206 mbsf (Fig. 11) indicates discrepancies that cannot be reconciled. Third, few laboratory velocity measurements are available above $206 \mathrm{mbsf}$. An alternative approach is to seek a reliable conversion from porosity to velocity, allowing us to use the numerous rebound-corrected laboratory measurements of porosity above $206 \mathrm{mbsf}$ to calculate a pseudovelocity log.

\section{EMPIRICAL VELOCITY MODELS}

Also shown in Figure 11 are three empirical models of the relationship of velocity to porosity for terrigenous sediments (matrix velocity of $5.08 \mathrm{~km} / \mathrm{s}$ ): (1) the Wyllie et al. (1956) time-average relationship, (2) the relationship of Raymer et al. (1980), and (3) a combination of the porosity/depth regression of Hamilton (1976a) with the velocity/depth regression of Hamilton (1979). As is now well known, Wyllie's equation greatly overestimates velocities for high-porosity sediments. The data for Site 646 display higher velocities for a given porosity than indicated by the Raymer curve, and a less linear relationship of velocity to porosity than indicated by the Hamilton curve (Fig. 11). In a companion paper, Busch (this volume) compares velocity to porosity using Hamilton's (1978) empirical relationship of velocity to density; he finds a good fit of the Site 646 data to this relationship.

A detailed comparison of porosity to velocity at Site 646 requires both in-situ data and removal of the effects of matrix velocity on velocity. Raymer et al.'s empirical relationship (1980) allows one to calculate velocity, given porosity, matrix velocity, density, grain density, fluid porosity, and fluid density. We used the log values for porosity (Fig. 1), pseudodensity (Fig. 9), and grain density (Fig. 8). We used a seawater fluid density of 1.042 $\mathrm{g} / \mathrm{cm}^{3}$, and a seawater fluid velocity of $1.510 \mathrm{~km} / \mathrm{s}$, based on the known effects of salinity, pressure, and temperature on fluid velocity (Sverdrup et al., 1942) and density (Schlumberger, 1972). The resulting pseudovelocity log (Fig. 12) underestimates velocities at the top of the velocity log by $0.12 \mathrm{~km} / \mathrm{s}$, based on comparison with log velocities. For porosities greater than $50 \%$, 


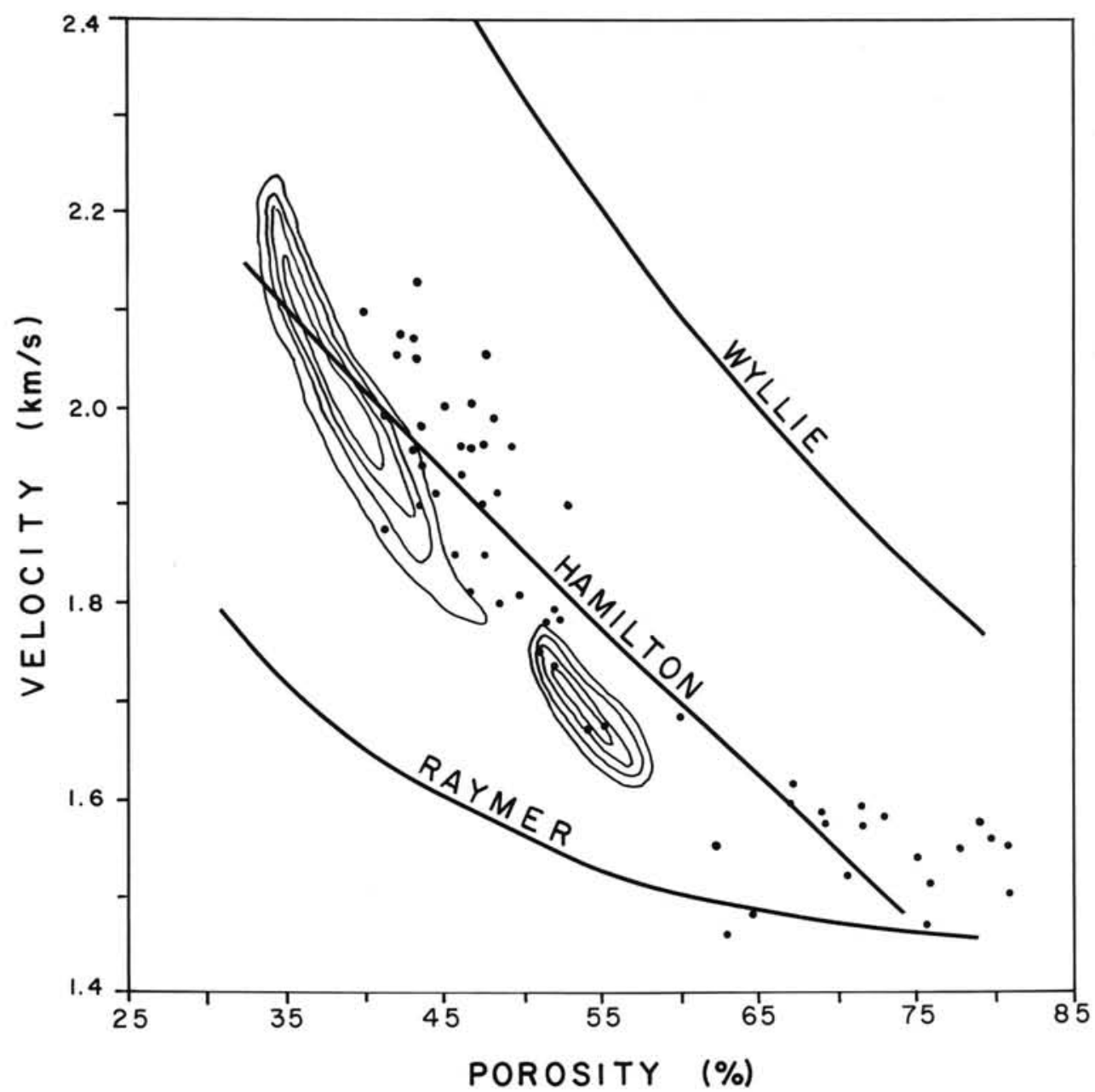

Figure 11. Cross plot of porosity vs. compressional wave velocity for Site 646 . Solid dots are laboratory measurements (without rebound correction), and the contours show data density for log measurements. Note that none of the three empirical relationships (Wyllie et al., 1956; Hamilton, 1976a, 1979; Raymer et al., 1980) predict the velocity vs. porosity relationship observed at Site 646 . Note also the discrepancy between log and laboratory measurements below $50 \%$ porosity, indicating that rebound is not simply moving both velocity and porosity measurements on cores along the velocity/porosity trend.

such as at the top of the logged interval, the Raymer et al. relationship indicates that sediment velocity is almost identical to fluid velocity and is insensitive to matrix velocity. A fluid velocity of $1.63 \mathrm{~km} / \mathrm{s}$ is required to achieve a match of observed with predicted velocities in this zone; such a fluid velocity is unrealistic.

Calculation of matrix velocity from mineralogy at each depth would be straightforward, if Site 646 contained no clay minerals. Matrix velocities of quartz $(5.44 \mathrm{~km} / \mathrm{s})$ and calcite $(6.25$ $\mathrm{km} / \mathrm{s}$ ) are well determined, and the matrix velocity of potassium feldspar $(4.3 \mathrm{~km} / \mathrm{s})$ is moderately well determined (Schlumberger, 1972, Raymer et al., 1980; Serra, 1987). However, "shale" matrix velocity can vary by a factor of two (Schlumberger, 1972), presumably depending on composition, shape, and arrangement of clay minerals (Hamilton and Bachman, 1982). Although Raymer et al. (1980) implied that their relationship is appropriate for clay-rich sediments, all the data sets shown for comparison with their model are quartz sediments.

Through iteration we found that a clay matrix velocity of 3.8 $\mathrm{km} / \mathrm{s}$ was required to obtain a match of observed with predicted velocities at the very bottom of Site 646. Because this estimate of clay matrix velocity assumed a priori that the Raymer et al. relationship is valid, our only possible test of this relationship was to compare observed with predicted velocities for the remainder of the logged interval.

The pseudovelocity log based on the Raymer et al. equation achieves an excellent match of high-frequency character with the velocity $\log$ (Fig. 12). This match results from the character similarity between velocity and porosity logs and the dominance of porosity over matrix velocity in the Raymer et al. equation. However, pseudovelocity values are different from actual velocities (Fig. 12), except in the lowest portion of the site, where a match was forced by our choice of clay matrix velocity. For Site 646 , the Raymer et al. equation overestimates the sensitivity of velocity to porosity changes for 450 to $600 \mathrm{mbsf}(1.9-2.1 \mathrm{~km} / \mathrm{s})$ and underestimates this sensitivity for 206 to $390 \mathrm{mbsf}$ (1.6-2.0 $\mathrm{km} / \mathrm{s}$ ). It may not be coincidental that all the data sets shown by Raymer et al. (1980) to corroborate their model were for velocities of less than $1.6 \mathrm{~km} / \mathrm{s}$ or greater than $2.3 \mathrm{~km} / \mathrm{s}$, which is outside the velocity range of the Site 646 sediments.

Hamilton (1979) presented an average velocity/depth trend for terrigenous sediments. Carlson et al. (1986) presented an average velocity/depth trend for all deep-sea sediments, based on Deep Sea Drilling Project data of predominantly terrigenous sediments. Both curves are in general agreement with velocities 


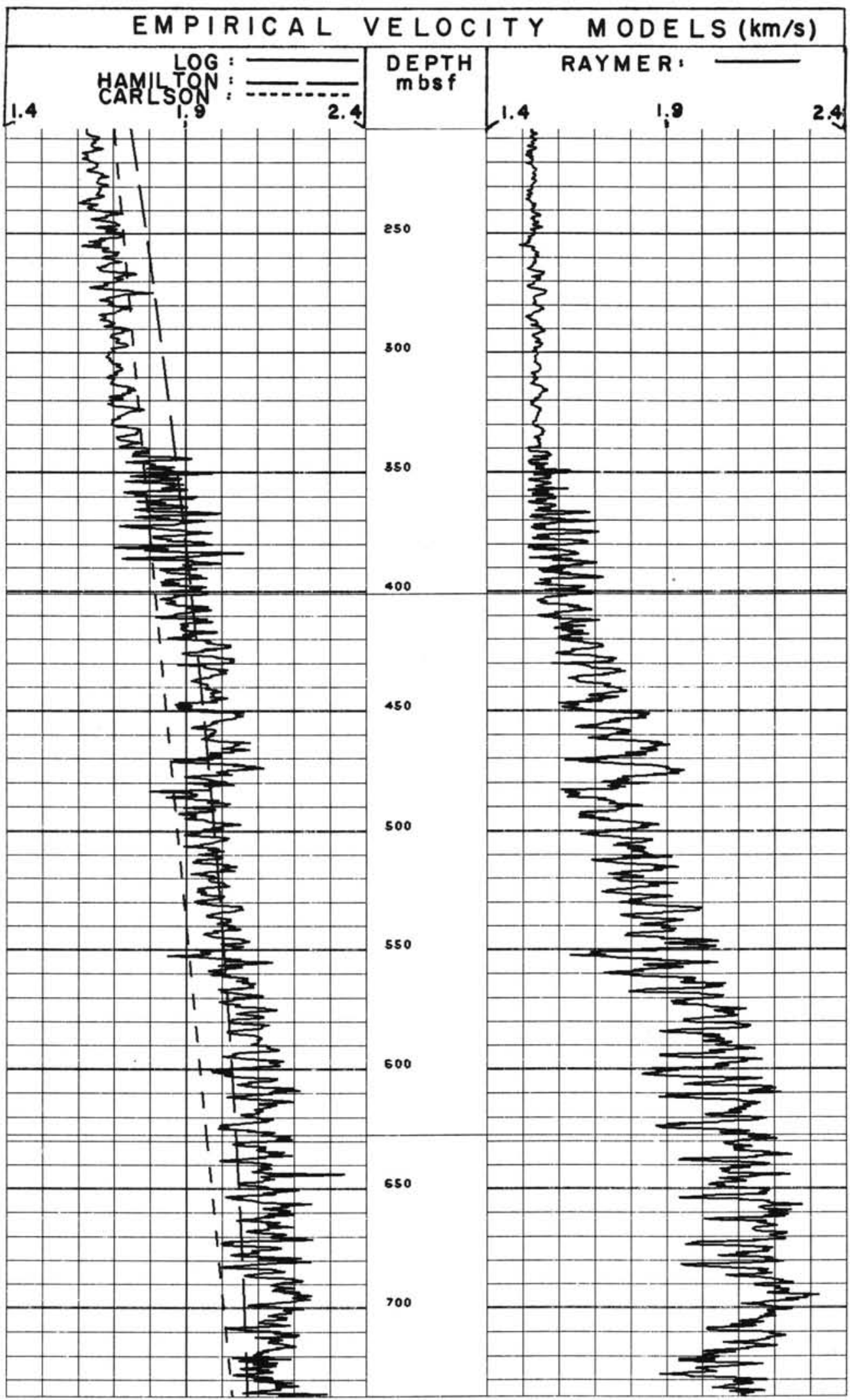

Figure 12. Comparison of logged velocity variations as a function of depth (solid line at left) with empirical velocity/depth curves of Hamilton (1979) and Carlson et al. (1986) and with a pseudovelocity log generated from Raymer et al.'s empirical relationship (1980). The Raymer et al. relationship correctly predicts that porosity fluctuations cause velocity fluctuations, but it substantially underestimates velocities everywhere except at the 650-700 mbsf calibration interval (see text). In contrast, the empirical curves approximately match the magnitude, but not the character, of observed velocity variations. 
at Site 646 and predict the observed trend with an accuracy of about 0.1 to $0.2 \mathrm{~km} / \mathrm{s}$. The Carlson et al. (1986) curve best matches the interval 206-345 mbsf, and the Hamilton (1979) curve best matches the interval 390-737 mbsf. Neither predicts as large an increase of velocity with depth as is observed. The differences are not surprising, in view of the known regional variations in porosity and mineralogy of terrigenous sediments. Note, however, that Carlson et al. (1986) concluded that sediment velocity is controlled by depth below seafloor (i.e., overburden), not by porosity, and perhaps not even by mineralogy. The excellent character match between porosity and velocity at Site 646 requires that Carlson et al.'s conclusion (1986) be rejected in favor of the more traditional explanation: porosity is the dominant control on velocity for sediment having porosities greater than $20 \%$, and the effect of overburden on velocity is indirect, arising from compaction-related porosity change.

\section{THEORETICAL VELOCITY MODELS}

Gassmann (1951) examined the implications of classic Hookean elastic equations for the elastic properties of marine sediments. The system bulk modulus $(k)$ of a mixture of sediment and pore water is related to velocity and bulk moduli of components by the equations,

$$
k=\rho V_{p}^{2}-4 / 3 \mu
$$

and

$$
k=\frac{k_{s}\left(k_{f}+Q\right)}{\left(k_{s}+Q\right)},
$$

where

$$
Q=\frac{k_{w}\left(k_{s}-k_{f}\right)}{\phi\left(k_{s}-k_{w}\right)}
$$

where

$$
\begin{aligned}
& V_{p}=\text { compressional wave velocity, } \\
& \mu=\text { shear or rigidity modulus, } \\
& \rho=\text { density, } \\
& k_{s}=\text { aggregate bulk modulus of mineral solids, } \\
& k_{w}=\text { bulk modulus of pore water, } \\
& k_{f}=\text { skeletal or frame bulk modulus, and } \\
& \phi=\text { fractional porosity. }
\end{aligned}
$$

For consistency with the usual units for velocity $(\mathrm{km} / \mathrm{s})$ and density $\left(\mathrm{g} / \mathrm{cm}^{3}\right)$, all moduli $\left(\right.$ dyne $\left./ \mathrm{cm}^{2}\right)$ can be multiplied by $10^{-10}$. For the logged interval of Site $646, \operatorname{logs}$ of $V_{p}, \rho$, and $\phi$ are available, $K_{w}=2.37 \times 10^{10}$ dyne $/ \mathrm{cm}^{2}, k$ is approximately $54.4 \times 10^{10}$ dyne $/ \mathrm{cm}^{2}$ for clayey silt (Hamilton, 1971) above $340 \mathrm{mbsf}$ and $50 \times 10^{10}$ dyne $/ \mathrm{cm}^{2}$ for silty clay (Hamilton, 1971) below 340 mbsf, and $k_{f}$ can be calculated from $\phi$, using Hamilton's empirical equation (1971) for silty clays:

$$
\log \left(10^{-8} \times k_{f}\right)=3.73580-4.25075 \phi .
$$

Wood (1941) simplified Equations 2 and 3, by assuming that the medium lacks rigidity and thus both $\mu$ and $k_{f}$ are zero:

$$
\frac{1}{\rho V_{p}^{2}}=\frac{\phi}{k_{w}}+\frac{1-\phi}{k_{s}}
$$

However, almost all deep-sea sediments possess some rigidity (Hamilton, 1971), and ignoring shear and skeletal moduli leads to a substantial underestimation of compressional wave velocity (Fig. 13).

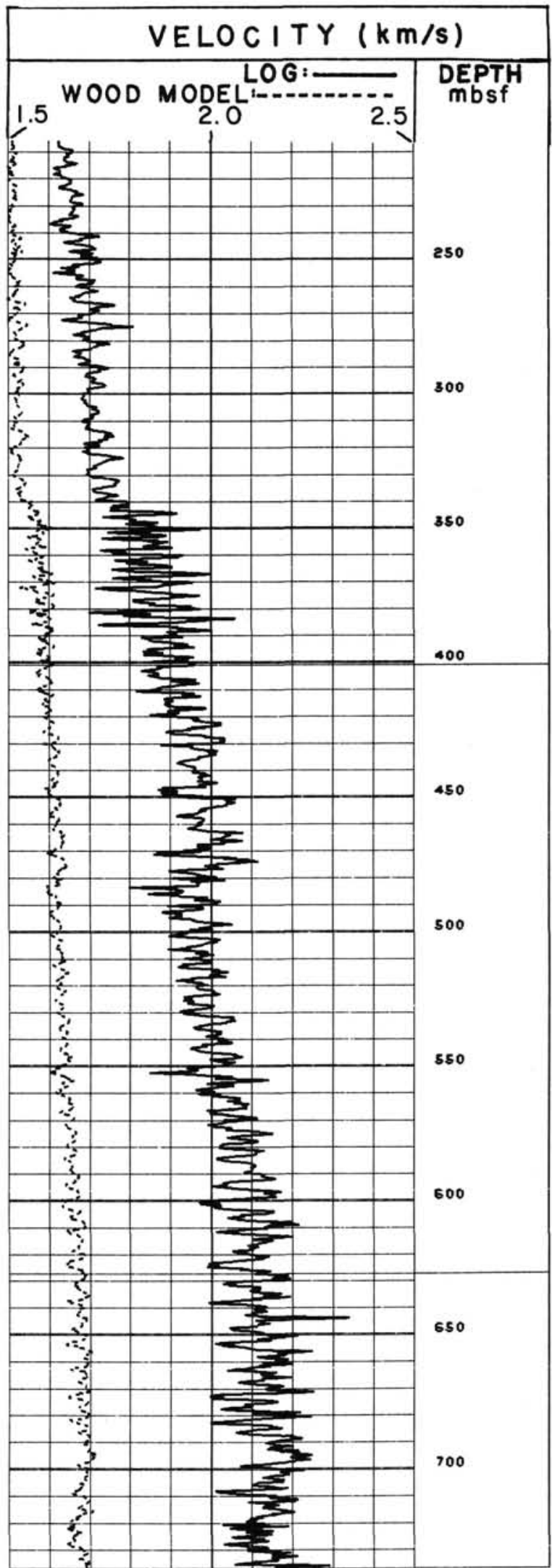

Figure 13. Comparison of observed velocity variations at Site 646 with pseudovelocities generated with Wood's model (1941). This model underestimates velocity, with an increasing discrepancy with increasing depth, because its assumption of no sediment rigidity is inappropriate for these (and most other) deep-sea sediments. 
Kuster and Toksöz (1974) and later Toksöz et al. (1976) refined Gassman's equations (1951) to consider the effect of pore geometry on acoustic properties. Pore geometry is particularly important to attenuation calculations. Lacking measurements of shear wave velocities, attenuation, and pore geometry, we cannot use their theoretical framework.

Lacking shear wave velocities, the rigidity modulus cannot be independently estimated, as it is sensitive to clay structure and interparticle bonding, but this value can be calculated from Equations 2 and 3 . The calculated rigidity modulus at Site 646 varies from $0.3 \times 10^{10} \mathrm{dyne} / \mathrm{cm}^{2}$ at $206 \mathrm{mbsf}$ to $2 \times 10^{10}$ dyne/ $\mathrm{cm}^{2}$ at 690-737 mbsf (Fig. 14), displaying an expected increase in rigidity with compaction. This trend in rigidity modulus corresponds to a gradual decrease in Poisson's ratio from 0.46 at 206 mbsf to 0.38 at $700-737$ mbsf. This trend in rigidity modulus implies a gradual increase in shear wave velocity from $0.47 \mathrm{~km} / \mathrm{s}$ at $206 \mathrm{mbsf}$ to $0.93 \mathrm{~km} / \mathrm{s}$ at $700-737 \mathrm{mbsf}$. Hamilton (1976b) developed an empirical curve of shear wave velocity as a function of depth (from 0 to $650 \mathrm{mbsf}$ ) for silty clays and turbidites, based on limited data below 36 mbsf. Our calculated shear wave velocities are $7 \%$ higher than this curve at 206 mbsf and $26 \%$ higher at 700-737 mbsf.

Rigidity modulus is strongly correlated with porosity at Site $646 ; 85.6 \%$ of the variance in rigidity modulus is accounted for by the regression equation,

$$
\log \left(\mu \times 10^{-10}\right)=1.231-2.782 \phi .
$$

A pseudovelocity (or predicted velocity) log was calculated from Equations 2 through 5. As shown in Figure 14, this log is nearly identical to the measured velocity log. The standard deviation of differences between the two is only $0.034 \mathrm{~km} / \mathrm{s}$. Much of the difference is associated with slight underestimation of peak-to-trough variations by the pseudovelocity log, partially because the sonic logging tool has higher vertical resolution than the resistivity tool. The comparison spotlights a bad velocity log point at $653 \mathrm{mbsf}$, probably caused by cycle skipping.

The pseudovelocity log is not independent of the velocity $\log$, because the log of rigidity modulus used in deriving Equation 5 was based on solving Equation 2. Nevertheless, the degree of agreement between velocity and pseudovelocity throughout the logged interval is remarkable. The sensitivity of raw rigidity modulus to possible errors in other parameters can be readily examined. Possible errors in input parameters are subjectively estimated to be $1.5 \%$ for velocity, $5 \%$ for density, $5 \%$ for porosity, $1.5 \%$ for fluid bulk modulus, and $15 \%$ for aggregate bulk modulus. Such errors would change the estimated rigidity modulus by $12 \%, 20 \%, 19 \%, 3 \%$, and $5 \%$, respectively, at the bottom of the logged interval. The possible error in the bulk modulus of pore water may be larger than the $1.5 \%$ estimate above. The value of $2.37 \times 10^{10} \mathrm{dyne} / \mathrm{cm}^{2}$ used above is appropriate for seawater at $0^{\circ} \mathrm{C}$ and sub-bottom pressures, but is too low if borehole temperatures are higher. As discussed previously, we assumed a bottomhole temperature of $18.4^{\circ} \mathrm{C}$ when calculating porosity from resistivity. However, depth of penetration of the sonic tool is much less than for resistivity, and a nearzero temperature seems appropriate. If an $18.4^{\circ} \mathrm{C}$ bottomhole temperature were assumed for determining $k_{w}$, the calculated rigidity modulus at the bottom of the hole decreases by $21 \%$ and the calculated Poisson's ratio increases from 0.38 to 0.41 .

A pseudovelocity log can also be calculated from reboundcorrected laboratory measurements of porosity and density, using Equations 1, 2, and 3. The calculated skeletal modulus and bulk modulus agree with those calculated from logs (Fig. 14), except in the interval $207-340$ mbsf, where laboratory porosities, and therefore system bulk moduli, are lower for laboratory measurements than logs. This difference is magnified in the cal- culated velocities. Below 340 mbsf, laboratory pseudovelocities are slightly lower than log velocities, because rebound-corrected densities are slightly higher than calculated log densities. Below 340 mbsf, the predicted velocities from laboratory data (Fig. 15) are generally similar to measured laboratory velocities (Fig. 10).

In the interval from 206 to $340 \mathrm{mbsf}$, velocities predicted from laboratory measurements are consistently about $0.1 \mathrm{~km} / \mathrm{s}$ less than log velocities (Fig. 15). This difference arises directly from the lower system bulk modulus (Fig. 15), and indirectly from higher porosities (Fig. 1) for laboratory data in this interval than for log data. We cannot distinguish among three possible causes for the velocity difference: (1) inaccuracy of laboratory porosity measurements (e.g., partial removal of bound water from clays by the heating to $104^{\circ} \mathrm{C}$ ), (2) actual porosity rebound larger than the rebound correction (Hamilton, 1976a) used, or (3) underestimation of porosities from resistivity (e.g., from inaccuracy of the assumed values for parameters $m$ and $a$ ), causing bias to the slope of the regression equation for rigidity modulus vs. porosity.

Estimation of velocities above 206 mbsf from laboratory measurements of velocity and density is sensitive to water velocity and calculated rigidity modulus. The regression equation for rigidity modulus from porosity is based on log porosities of $33 \%$ to $58 \%$, less than the laboratory porosities of $59 \%$ to $82 \%$ for 0 to 206 mbsf. Extrapolation of any regression equation beyond the range of input data is hazardous. However, such an extrapolation yields a predicted rigidity of $0.10 \times 10^{10}$ dyne $/ \mathrm{cm}^{2}$ at $80 \%$ porosity, quite similar to observed values of $0.08-0.15 \times 10^{10}$ dyne $/ \mathrm{cm}^{2}$ for deep-sea terrigenous sediments of $80 \%$ porosity (Hamilton, 1971). The low skeletal and rigidity moduli expected and calculated for near the seafloor indicate calculated velocities are insensitive to the uncertainties in these parameters. Neglecting rigidity modulus entirely for the top 20 m reduces the calculated velocity by only $0.03 \mathrm{~km} / \mathrm{s}$.

The calculated velocities of 1.47 to $1.49 \mathrm{~km} / \mathrm{s}$ for the top 20 $\mathrm{m}$ are slightly lower than the water velocity of $1.51 \mathrm{~km} / \mathrm{s}$, as expected for porosities of $75 \%$ to $82 \%$ (Hamilton, 1976b). In contrast, measured velocities for these sediments were 1.50-1.58 $\mathrm{km} / \mathrm{s}$, slightly faster than water velocity. Either the Hamiltonframe measurements for these soupy sediments have affected velocity through compression of the sample (Srivastava, Arthur, et al., 1987a), or elastic properties of the surface sediments at Site 646 were affected slightly by the coring process, or these sediments have an anomalously high rigidity modulus of about $0.2-0.4 \times 10^{10}$ dyne $/ \mathrm{cm}^{2}$.

\section{MERGED LOGS OF VELOCITY AND DENSITY}

Detailed seismic stratigraphic interpretation of the vicinity of Site 646 (Arthur et al., this volume) requires a detailed link between seismic traveltime and hole depth. Only with such a link can we interpret regional variations of seismic reflectors in terms of the age and sedimentology of Site 646. A synthetic seismogram for the site requires velocity and density logs, ideally for the entire drilled sequence. Merging of laboratory and log measurements is needed.

Below 206 mbsf, the log velocity and pseudodensity data are preferable to laboratory data, for three reasons. First, and most important, these log data are continuous and representative, while the laboratory measurements are widely spaced and conducted using very small samples of the cored sequence. Second, $\log$ velocities are in-situ measurements, while the laboratory velocity measurements are difficult to extrapolate to in-situ conditions. Third, some laboratory velocity measurements are clearly inaccurate (Fig. 10), while accuracy of some other measurements is uncertain. The slight difference between log pseudodensities and rebound-corrected laboratory densities below 340 $\mathrm{m}$ does not diminish the appropriateness of using pseudoden- 


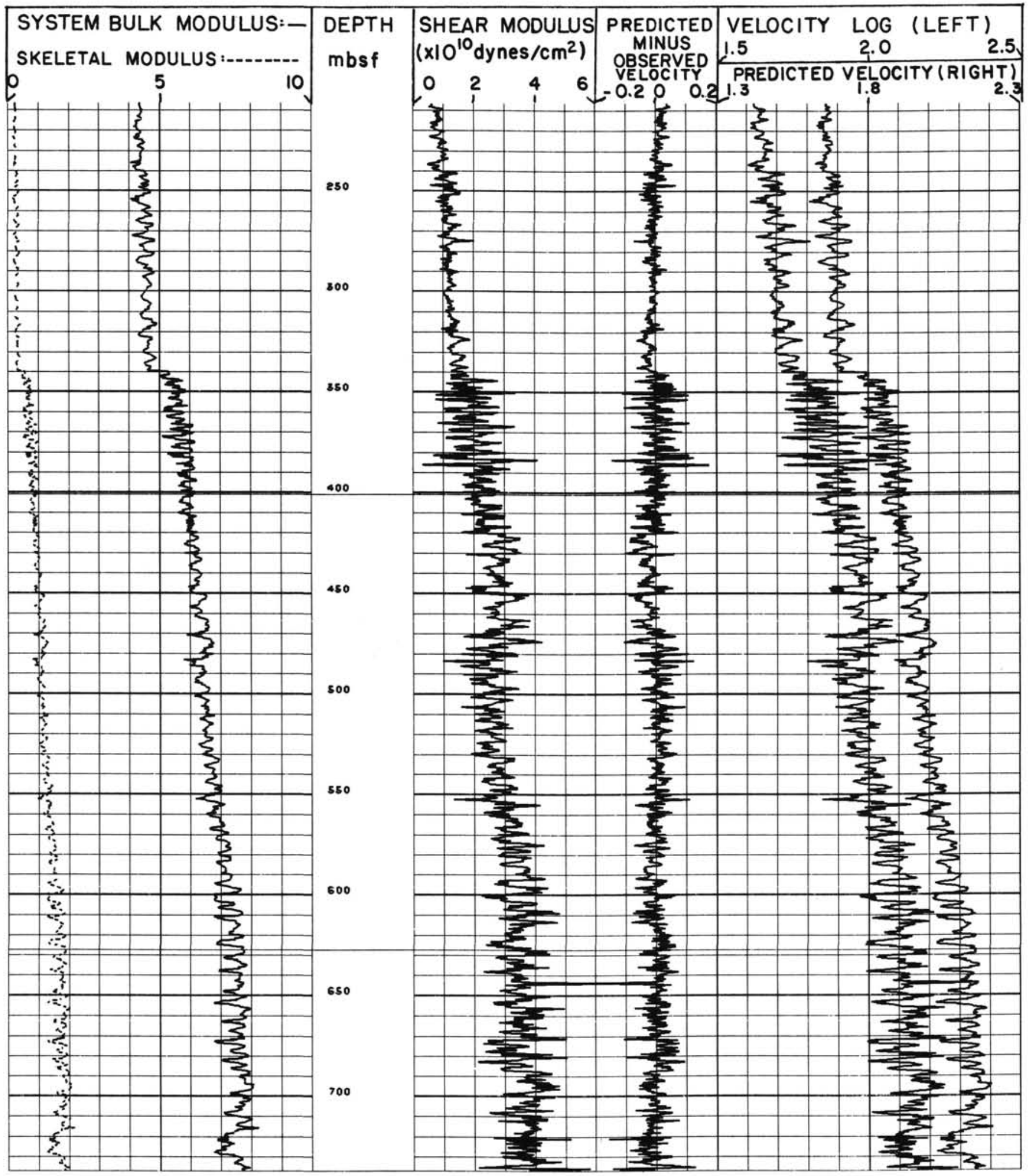

Figure 14. Elastic properties as a function of depth at Site 646 . The system bulk, skeletal, and shear (or rigidity) moduli (in $10^{10} \mathrm{dyne} / \mathrm{cm}^{2}$ ) were computed from Equations 2 and 3. The pseudovelocity (or predicted velocity) log at right was determined from porosity and density logs, using Equations 2 through 5 . Note that the pseudovelocity log display is offset two divisions from the velocity log; the two logs are so similar (track 3 ) that overlay with the same plot range would make it difficult to distinguish between them. 


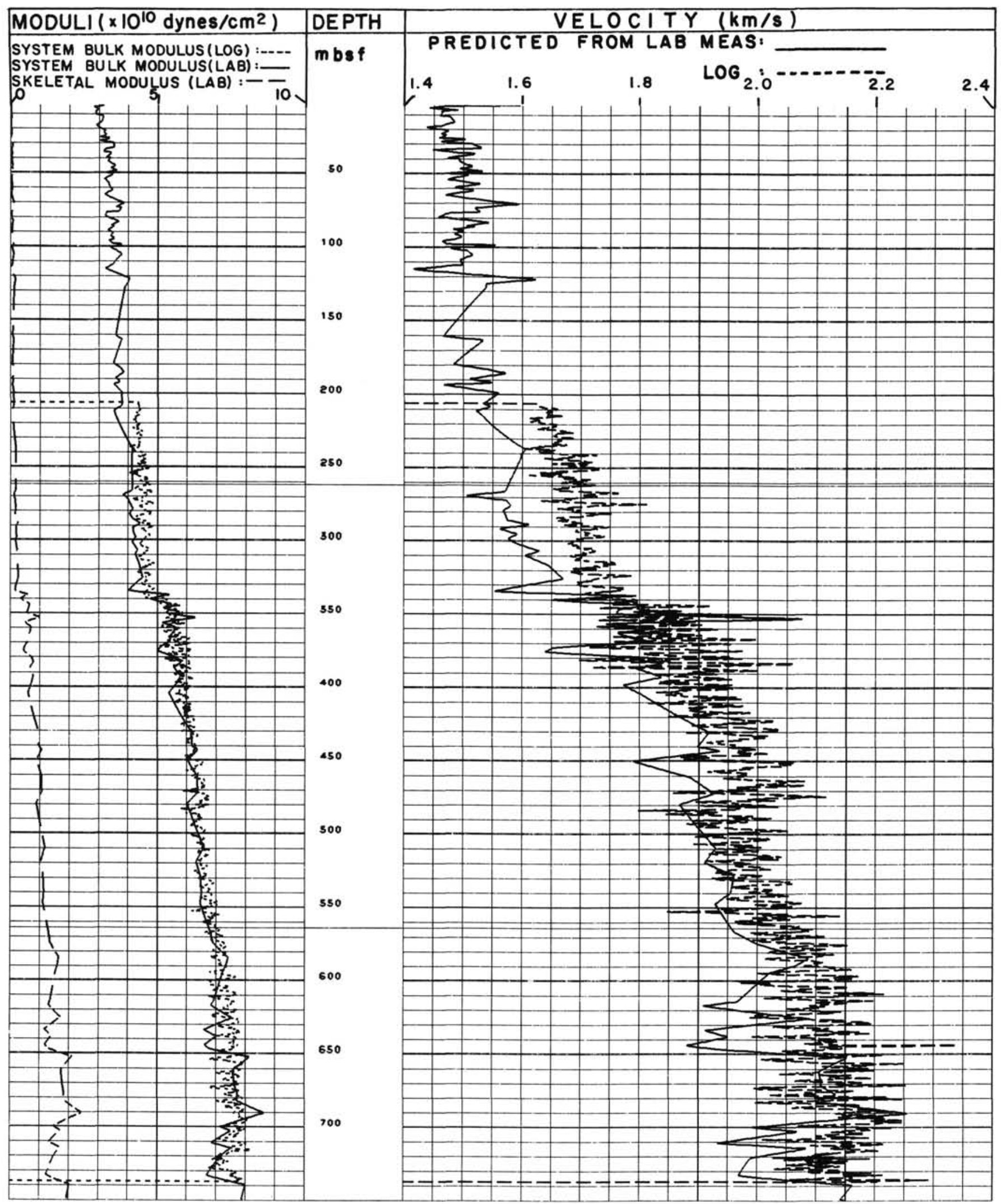

Figure 15. Comparison of $\log$ (dotted lines) with laboratory (solid and dashed lines) estimates of elastic properties. Laboratory estimates are based on applying Equations 2 through 5 to core measurements of porosity and density. Note that predicted velocities are similar to laboratory measurements of velocity (Fig. 10) but less than in-situ velocities. 
sity, rather than laboratory measurements; impedances would be trivially affected by a slight underestimation of density (if present) in the pseudodensity log.

Above 206 mbsf, no log velocities or densities are available, and laboratory measurements are used in the merged log. A single anomalous density measurement at 140 mbsf (Fig. 9) is excluded. This measurement may be accurate (compare Fig. 1 with Fig. 8) but nonrepresentative; GRAPE densities at this depth are substantially lower (Busch, this volume). We use calculated velocities of Figure 15 in preference to measured velocities of Figure 10, because the laboratory measurements of porosity and density are much more abundant and reliable than the velocity measurements. To reconcile these calculated velocities with log velocities between 206 and 340 mbsf and to avoid an artificial velocity jump at the 206-m junction of laboratory and $\log$ data, we were forced to multiply the calculated velocities by a ramp function, from 1.0 at the seafloor to 1.05 at 206 mbsf. Although theoretically unsatisfying, this ramp function captures the character of the velocity fluctuations that must accompany observed porosity changes, while avoiding the unresolved question of why laboratory and log porosities are slightly different in the interval 206-340 mbsf.

The final merged velocity and density logs are shown in Figure 16. These logs are considered to be very good in the intervals 0-100 mbsf and 206-737 mbsf, but less reliable in the interval 100-206 mbsf, where data are sparsest and velocities are most uncertain.

\section{CONCLUSIONS}

Only with both downhole geophysical logs and laboratory measurements on cores can one completely assess the reliability of either data type. Because the two data types use different measurement techniques, assumptions, and corrections, comparison of the two data types can test the reliability of these assumptions and corrections. At Site 646, as at many other sites, the two data types complement each other nicely: core recovery and therefore the potential for laboratory measurements is highest in the top $100 \mathrm{mbsf}$, and openhole logging at this site begins at 206 mbsf (more commonly at about 100 mbsf).

The mineralogy of Site 646 was determined for 206-737 mbsf by inversion of three logs: bound water, potassium, and uranium/ thorium ratio. Ideally, such an inversion should be checked by comparison with detailed XRD analyses, but none were available from Site 646. Comparison of log mineralogy with smoothed mineralogical abundances from smear slides showed a general agreement, but also highlighted potential shortcomings of smearslide mineralogy: widely spaced samples, overestimation of calcite and quartz, and underestimation of feldspar.

Reliable determination of porosity is important for calculating clay content accurately and is essential for determining acoustic properties. During our determination of porosity from a resistivity $\log$, the largest uncertainty was temperature of the formation near the borehole, because of the effect of temperature on resistivity of formation water. During our determination of insitu porosity from laboratory measurements of core porosity, the largest uncertainty was the amount of rebound. Hamilton's empirical rebound correction (1976a) appears to work well for Site 646 and leads to a generally good agreement of log porosities with laboratory ones.

The largest change in mineralogy and porosity at Site 646 occurs at 340 mbsf. Quartz content decreases (downward) from $45 \%$ to $20 \%$ at this depth, and clay content increases from $45 \%$ to $65 \%$. This horizon marks the deepest occurrence of significant siliceous microfossils (Srivastava, Arthur, et al., 1987b). Abundance of siliceous microfossils is always below the resolving power of mineralogic log inversion at Site 646, but the effect of siliceous microfossils on porosity is substantial: both log and laboratory measurements of porosity indicate a sudden decrease of 6 porosity units at this depth, despite the higher clay content below 340 mbsf.

A high-frequency (5-10 m) cyclicity of porosity and mineralogy occurs throughout Site 646 . Below about 400 mbsf, the porosity fluctuations are caused by cyclical variation in clay mineral abundance, with higher clay content associated with higher porosity. Above $400 \mathrm{mbsf}$, and especially in the interval 206-340 mbsf, variations in opal content probably cause these porosity fluctuations.

Porosity is the dominant control on acoustic properties at Site 646. Compressional wave velocity, density, system bulk modulus, and rigidity (shear) modulus are all closely linked to porosity and display the same gradual compaction effect and high-frequency variations as porosity. A pseudodensity log, based on porosity, mineralogy, and their theoretical effects on density, shows good agreement with laboratory measurements of core density. A pseudovelocity log, based on porosity, pseudodensity, and on the theoretical equations of Gassmann (1951), is almost identical to the velocity $\log$. The only exception to the overall dominance of porosity over mineralogy in affecting acoustic properties is the major lithologic change at 340 mbsf; at this depth, the change in clay content increases the density contrast and decreases the velocity contrast, compared with the effect of porosity alone.

The strongest test of any empirical model is its predictive value for new data sets. Empirical curves of porosity, density, and compressional wave velocity as a function of depth for terrigenous sediments fit our data for Site 646 well. In contrast, the empirical curve for shear velocity vs. depth diverges from the Site 646 data; the limited database for the curve and high regional variability in rigidity of terrigenous sediments are probably responsible for this divergence.

Too little attention has been paid to the velocity/porosity relationship for high-porosity sediments. Empirical relationships of velocity to porosity fit our data poorly. For logs from Site 646 , we had much greater success with Gassmann's theoretical relationships (1951) than with empirical relationships. However, the former had limited success in predicting velocities from laboratory measurements of density and porosity. Further, we are not confident that the empirical relationship between shear modulus and porosity that worked so successfully at Site 646 will be of comparable usefulness elsewhere, because of regional variations in clay composition, clay and pore geometry, and diagenesis. Thus, we conclude that there is still no reliable method of estimating velocity from porosity and/or density for high-porosity deep-sea sediments, unless at least a few reliable velocity measurements are available to constrain the solution. At Site 646 , the laboratory measurements of velocity could not have fulfilled this calibration role; we were unable to reconcile these measurements with in-situ velocities through rebound correction.

This study suggests that three relatively minor enhancements to the Ocean Drilling Program would have a major impact on the fruitfulness of future studies of the elastic properties of penetrated sediments:

1. The ability to measure velocity and porosity of core samples at in-situ pressures and temperatures would greatly increase the reliability of these measurements and decrease uncertainties of rebound correction.

2. Measurement of downhole temperature and, ideally, of formation water resistivity would greatly increase the accuracy of porosity determined from resistivity logs.

3. A shear-source logging tool would provide the first routine measurements of shear wave velocities for high-porosity sediments and a much needed internal coinsistency check for calculated acoustic properties. 


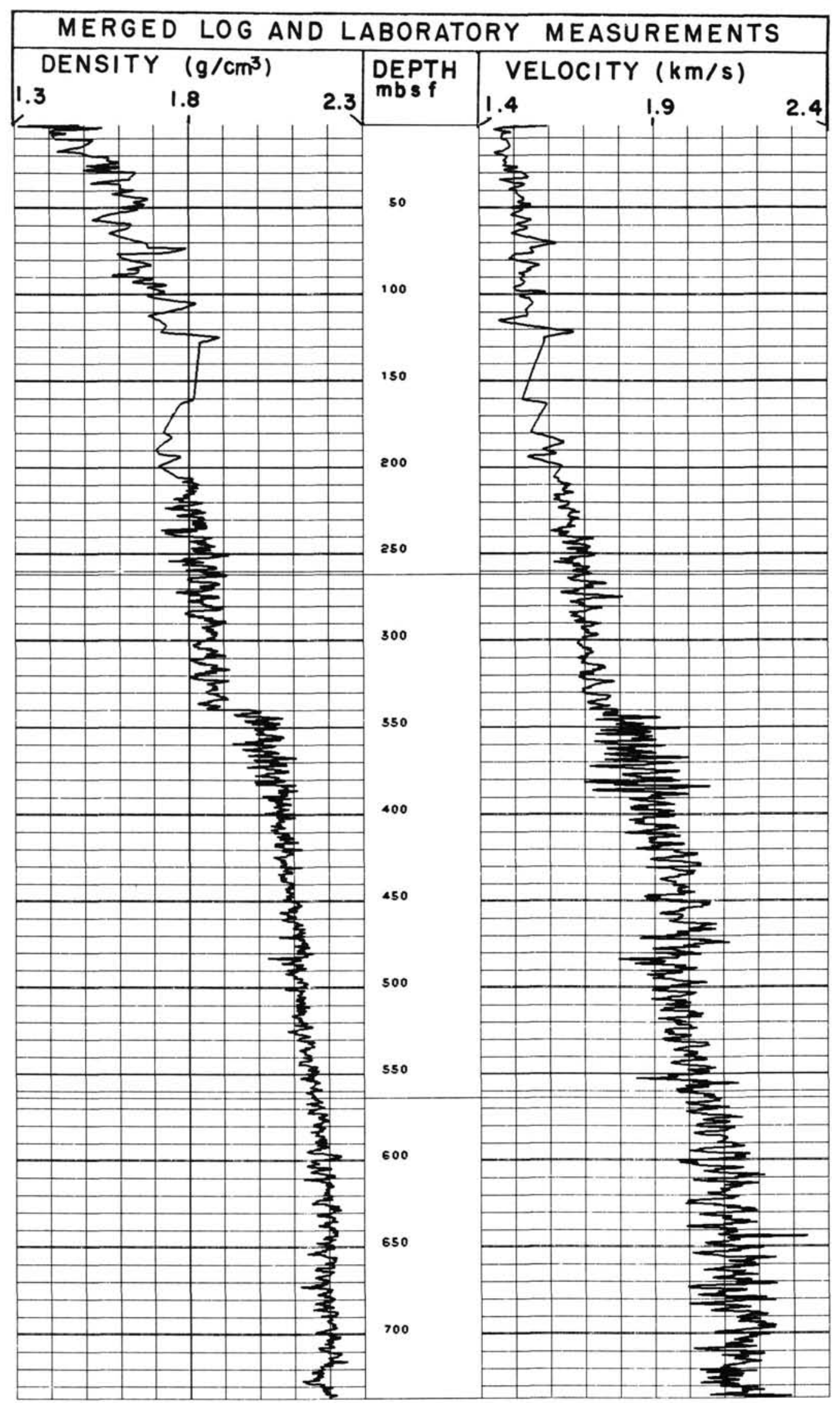

Figure 16. Final merged logs for velocity and density fluctuations throughout the depth interval of Site 646, based on downhole logs below 206 mbsf and laboratory measurements on cores above 206 mbsf, with processing described in the text. 


\section{ACKNOWLEDGMENTS}

This study was supported by NSF Grants TAMRF 76286 to LamontDoherty and TAMRF 76574 to the Univ. of Rhode Island.

\section{REFERENCES}

Archie, G. E., 1942. The electrical resistivity $\log$ as an aid in determining some reservoir characteristics. Trans Am. Inst. Min. Metall. Pet. Eng., 146:54-63.

Carlson, R. L., Gangi, A. F., and Snow, K. R., 1986. Empirical reflection traveltime vs. depth and velocity vs. depth functions for the deep-sea sediment column. J. Geophys. Res., 91:8249-8266.

Clavier, C., Coates, G., and Dumanoir, J., 1977. The theoretical and experimental bases for the "Dual Water" model for the interpretation of shaly sands. Proc. Soc. Pet. Eng., 52nd Annu. Fall Conf., Pap. SPE 6859.

Doveton, J. H., 1986. Log Analysis of Subsurface Geology: Concepts and Computer Methods: New York (Wiley).

Fertl, H. H., 1979. Gamma Ray Spectral Data Assists in Complex Formation Evaluation: Houston (Dresser-Atlas).

Gassmann, F., 1951. Elastic waves through a packing of spheres. Geophysics, 16:673-685.

Goldberg, D., and Gant, W. T., 1988. Shear-wave processing of sonic $\log$ waveforms in a limestone reservoir. Geophysics, 53:668-676.

Goldberg, D., Wilkens, R. H., and Moos, D., 1987. Seismic modeling of diagenetic effects in Cenozoic marine sediments at Deep Sea Drilling Project Sites 612 and 613. In Poag, C. W., Watts, A. B., et al., Init. Repts. DSDP, 95: Washington (U.S. Govt. Printing Office), 589-599.

Hamilton, E. L., 1971. Prediction of in-situ acoustic and elastic properties of marine sediments. Geophysics, 36:225-284. 1976a. Variations of density and porosity with depth in deepsea sediments. J. Sediment. Petrol., 46:280-300. , 1976b. Shear-wave velocity vs. depth in marine sediments: a review. Geophysics, 41:985-996. , 1978. Sound velocity-density relations in seafloor sediments and rocks. J. Acoust. Soc. Am., 63:266-377. 1979. Sound velocity gradients in marine sediments. J. Acoust. Soc. Am., 65:909- 922.
Hamilton, E. L., and Bachman, R. T., 1982. Sound velocity and related properties of marine sediments. J. Acoust. Soc. Am., 72:1891-1904.

Kimball, C. V., and Marzetta, T. L., 1984. Semblance processing of borehole acoustic array data. Geophysics, 49:274-281.

Kuster, G. T., and Toksöz, M. N., 1974. Velocity and attenuation of seismic waves in two-phase media: Part I-theoretical formulation, Part II-experimental results. Geophysics, 39:587-607.

Pape, H., and Worthington, P. F., 1983. A surface-structure model for the electrical conductivity of reservoir rocks. Trans Eur. Formation Evaluation Symp., 8:1-9.

Raymer, L. L., Hunt, E. R., and Gardner, J. S., 1980. An improved sonic transit time-to-porosity transform. Trans., SPWLA 21st Annu Log. Symp., Pap. P.

Schlumberger Ltd., 1972. Log Interpretation, Vol. I-Principles: New York (Schlumberger Ltd.).

Serra, O., 1987. Fundamentals of Well-Log Interpretation, 2. The Interpretation of Logging Data: Amsterdam (Elsevier).

Srivastava, S. P., Arthur, M., et al., 1987a. Proc. ODP, Init. Repts., 105: College Station, TX (Ocean Drilling Program), 21-41.

Srivastava, S. P., Arthur, M., et al., 1987b. Proc. ODP, Init. Repts., 105: College Station, TX (Ocean Drilling Program), 419-674.

Sverdrup, H. U., Johnson, M. W., and Fleming, R. H., 1942. The Oceans: Their Physics, Chemistry, and General Biology: Englewood Cliffs, NJ (Prentice-Hall).

Toksöz, M. N., Cheng, C. H., and Timur, A., 1976. Velocities of seismic waves in porous rocks. Geophysics, 41:621-645.

Waxman, M. H., and Smits, L.J.M., 1968. Electrial conductivities in oil-bearing shaly sands. Soc. Pet. Eng. J., 8:107-122.

Winsauer, W. O., Shearin, H. M., Jr., Masson, P. H., and Williams, M., 1952. Resistivity of brine saturated sands in relation to pore geometry. AAPG Bull., 36:253-277.

Wood, A. B., 1941. A Textbook of Sound: London (G. L. Bell).

Wyllie, M.R.J., Gregory, A. R., and Gardner, L. W., 1956. Elastic wave velocities in heterogeneous and porous media. Geophysics, 21:4170.

Date of initial receipt: 22 January 1988

Date of acceptance: 29 September 1988

Ms 105B-146 